Federal Reserve Bank of Dallas

Globalization and Monetary Policy Institute

Working Paper No. 113

http://www.dallasfed.org/assets/documents/institute/wpapers/2012/0113.pdf

\title{
Hedging Against the Government: A Solution to the Home Asset Bias Puzzle*
}

\author{
Tiago C. Berriel \\ EPGE \\ RGV-Rio \\ Saroj Bhattarai \\ Pennsylvania State University
}

April 2012

\begin{abstract}
This paper explains two puzzling facts: international nominal bonds and equity portfolios are biased domestically. In our two-country model, holding domestic government nominal debt provides a hedge against shocks to bond returns and the impact on taxes they induce. For this result, only two features are essential: some nominal risk and taxes falling only on domestic agents. A third feature explains why agents choose to hold primarily domestic equity: government spending falls on domestic goods. Then, an increase in government spending raises the returns on domestic equity, providing a hedge against the subsequent increase in taxes. These conclusions are robust to a wide range of preference parameter values and the incompleteness of financial markets. A calibrated version of the model predicts asset holdings that quantitatively match the data.
\end{abstract}

JEL codes: F30, F41, G11

* Tiago Berriel, Praia de Botafogo 190, 1101, Rio de Janeiro, Brazil. 55-21-3799-5844. Tiago.berriel@fgv.br. Saroj Bhattarai, 615 Kern Building, Pennsylvania State University, University Park, PA 16802. 814-863-3794. Sub31@psu.edu. We thank without implicating Arpita Chatterjee, Nicolas Coeurdacier, John Duca, Chris Erceg, Luca Guerrieri, Jonathan Heathcote, Oleg Itskhoki, Nobu Kiyotaki, Fernanda Nechio, seminar participants at Princeton University, Far East Meeting of the Econometric Society, the Fed Board, Cornell-Penn State Macro Workshop, Ipea, IBMEC-Rio, PUC-Rio, Fed New York, University of Arkansas, EEA/ESEM, and especially, Ricardo Reis and Chris Sims for helpful suggestions and comments. First Circulated Draft: Aug 2008. This Draft: March 2012. The views in this paper are those of the authors and do not necessarily reflect the views of the Federal Reserve Bank of Dallas or the Federal Reserve System. 


\section{Introduction}

While international trade in bonds and equity has increased greatly in the last two decades, country portfolios still show a sizeable bias towards domestic assets. For example, Burger and Warnock (2003) find that foreign bonds comprised about $6 \%$ of U.S. investors' bond portfolios in 1997 and $4 \%$ in 2001 and Kyrychenko (2005) finds that around $95 \%$ of U.S. bond holders choose to hold only domestic bonds. Moreover, Nechio (2009) shows that in the U.S., only around $2 \%$ of government bond holders hold any kind of foreign bonds, including indirect holdings through mutual funds. ${ }^{1}$ Corroborating this evidence further, Fidora et al (2003) show that there is substantial home bias in bond holdings for several advanced countries. ${ }^{2}$ Such evidence points towards significant domestic bias in international bond portfolios. Similarly, table 1, reproduced from Coeurdacier et al (2007), shows that international equity portfolios are heavily biased domestically as countries hold a significantly higher fraction of their portfolios in domestic equity as compared to the world market capitalization share of their stock markets.

From the perspective of standard international macroeconomic models, the degree of home asset bias observed in the data is a long-standing puzzle, as it implies a lack of international risk sharing among countries. For equity holdings, Lucas (1982) showed in a two-country economy with trade in claims to domestic and foreign endowments that perfect risk sharing against endowment shocks can be supported by each agent owning half the claims to the home endowment and half to the foreign endowment. ${ }^{3}$ For debt holdings, if there are idiosyncratic risk to returns on bonds, one would similarly expect agents to diversify their portfolio holdings.

Our baseline model that yields exact analytical solutions is a standard twocountry two-good two-period endowment economy model with trade in equities and one-period government nominal bonds. The government issues debt and taxes domestic agents to finance its expenditure on the domestic good.

\footnotetext{
${ }^{1}$ Burger and Warnock (2003) use the 1997 and 2001 benchmark surveys of U.S. Holdings of Foreign Securities while Kyrychenko (2005) and Nechio (2009) use the Survey of Consumer Finances.

${ }^{2}$ In particular, they compute home bias for bonds in Japan, U.K., Germany, Italy, and France using IMF data. They also show that in fact, home bias in bonds is stronger than home bias in equities.

${ }^{3}$ Moreover, in a production economy model, Baxter and Jermann (1997) show that optimal portfolio holdings involve shorting domestic assets. This implies that the data is highly at odds with the theory.
} 
In this frictionless set-up with complete markets, we show that equilibrium portfolio holdings are biased completely towards domestic debt and equity. To our knowledge, this is the first paper to generate joint home bias in both nominal government debt and equity in a standard frictionless international macroeconomic model.

What drives our results? Holding domestic bonds offers insurance against shocks that lead to a revaluation of government debt, such as innovations to the price level. For example, in the case of bonds with nominal returns known one period in advance, the risk that agents face is in the form of the price level next period. If the price level is higher than expected at home, then agents will realize a lower real return on domestic bonds. With a higher price level at home however, the expected value of future taxes on domestic agents is lower since the real value of debt outstanding has decreased and the intertemporal government budget constraint has to be satisfied. Therefore, real return on domestic bonds and taxes co-move positively and, since the government taxes only domestic agents, holding only domestic bonds achieves optimal risk-sharing.

Holding only domestic equity is an optimal portfolio decision because government spending falls on domestic goods. ${ }^{4}$ Then, a positive domestic government spending shock will increase the relative price of the domestic good. This means that the relative return of claims on the domestic good is higher compared to the claims on the foreign good. Since government spending has increased, in order to fulfill the intertemporal government budget constraint, domestic taxes have to increase. Therefore, to hedge against this risk, agents will want to hold an asset that offers a relatively higher return. Domestic equity is precisely such an asset.

These basic mechanisms that lead to home asset bias are fully operative when we relax the simplifying assumptions of our baseline model. The only requirements for home bias in nominal government debt are the presence of some debt revaluation risk (such as nominal risk) that can be hedged through nominal bonds and taxes falling relatively more on the domestic agent. We view these features as a realistic description of the behavior of the governments of at least the industrialized countries. Similarly, the home equity bias result

\footnotetext{
${ }^{4}$ We are following a long standing tradition in international macroeconomic models that assumes that government spending falls relatively more on domestic (or non-traded) goods. For a recent example, see Corsetti and Pesenti (2001).
} 
is robust to some government spending on foreign goods as long as government spending shocks fall relatively more on domestic goods compared to foreign goods. A general result of our paper is that to generate equity home bias, a sufficient condition is for the government's consumption to be roughly more biased than the consumer's towards domestic goods. Moreover, while in our baseline model, we consider complete markets to derive analytical solutions and isolate the basic mechanisms at work, we relax this assumption and show that our results on home asset bias are still valid under imperfect international risk-sharing.

To assess the empirical relevance of our paper in resolving the home asset bias puzzle, we undertake two exercises. First, we conduct a model based quantitative evaluation of our results. We present a fully dynamic version of the two country model with production, numerically solve for portfolio choice under the realistic assumption of incomplete markets and distortionary taxes, and show that a calibrated model is able to quantitatively match the portfolio holdings observed in the data. ${ }^{5}$ Second, we discuss existing empirical evidence and conduct additional empirical exercises that validate the key mechanisms of our paper. We tackle questions such as: does the data provide support for a positive correlation between realized real returns on domestic bonds and taxes? Is this correlation driven by inflation movements? Is there evidence for a positive correlation between domestic equity returns and government spending? Is government spending more biased towards domestic goods compared to private consumption?

Home bias in nominal government debt has been neglected in the literature, while home bias in equity has been extensively addressed. Since this literature is quite voluminous, here we discuss a set of approaches that are directly relevant for comparison with our set-up. ${ }^{6}$ One approach, exemplified in important papers by Kollmann (2006) and Obstfeld (2006), focuses on a preference bias of agents towards consuming domestic goods. This bias is motivated by the empirical observation that the majority of private consumption falls on domestic goods. Then, with only country specific endowment shocks, these models generate domestic bias in equity if the elasticity of substitution between domestic and foreign goods is less than one. The intuition for this

\footnotetext{
${ }^{5}$ Therefore, while our basic mechanism behind debt bias is reminiscent of the Ricardian equivalence result in Barro (1974), our results hold under a more general environment.

${ }^{6}$ For a recent survey of this literature, see Coeurdacier and Rey (2011).
} 
result is the following. When a positive endowment shock hits the domestic economy, the terms of trade deteriorates and the real exchange rate depreciates. Since the domestic agent is biased towards consuming the domestic good and that good has become cheaper, risk-sharing involves holding an asset whose returns are relatively lower. With an elasticity of substitution lower than one, the deterioration in terms of trade is so strong that the return on domestic equity is in fact lower than that on foreign equity. Therefore, agents are biased towards holding domestic equity.

In these models, equity positions are used to hedge against real exchange rate risk and they imply a high and positive correlation between the real exchange rate and relative equity returns. As van Wincoop and Warnock (2006) point out however, the empirical evidence for this mechanism appears to be not very strong since the data shows a very low correlation. Compared to this literature, our results hold even when we do not assume any preference bias in consumption, that is, when there is no real exchange rate movement. This leads to a zero correlation between the real exchange rate and relative equity returns. Therefore in our mechanism, equity positions are not used to hedge against real exchange rate risk. Even for the empirically realistic case of consumption home bias and hence real exchange rate movement, since our incomplete markets model is driven by both supply and government spending shocks, the correlation between the real exchange rate and equity returns is not pinned down to be high and positive. Moreover, our results are robust to a wide range of values for the elasticity of substitution between domestic and foreign goods, including whether it is greater than or less than one.

A second important approach, best exemplified by Heathcote and Perri (2007), explains the observed equity bias by a negative correlation between relative domestic equity returns and relative non-diversifiable labor income. In their business cycle model with production and investment, domestic equity bias is an optimal way to risk share against country specific productivity shocks. Given a positive productivity shock, labor income is higher and therefore agents will hold primarily domestic equity if the return on it is lower than foreign equity. In their set-up, equity is a claim to the capital stock and the relative price of capital is equal to the relative price of consumption. A positive productivity shock depreciates the real exchange rate and thereby, leads to a devaluation of the domestic capital stock. Under a range of parameter values, this devaluation is so strong that the return on domestic equity is lower 
than foreign equity. This mechanism relies on a preference bias towards the domestic goods in consumption and investment, which is not the case in our baseline model. Overall, our paper is independent from and complementary to theirs, especially since we generate substantial home bias in equity holdings even in a model without investment. ${ }^{7}$

In another interesting approach, Coeurdacier et al (2007) generate home bias in equities without requiring equity positions to hedge against real exchange rate risk. In their endowment economy model, a new set of shocks, called redistributive shocks, redistribute income randomly between equity and non-diversifiable income. These break the perfect correlation between the real exchange rate and relative equity returns while creating an incentive to hold domestic equity. In the presence of such shocks, to hedge against them, agents want to hold domestic equity since in states of the world where due to a positive redistribution shock, domestic equity income is lower, non-diversifiable income will be higher. ${ }^{8}$ In our paper, the shocks that we use, government expenditure shocks, have already been extensively used in the literature, for example in Obstfeld (1989) and Backus, Kehoe and Kydland (1994). ${ }^{9}$

\section{Simple Model}

We start with a simple model for two reasons. First, it enables us to derive exact analytical solutions that provide intuition for the mechanism behind our results. Second, it makes clear which assumptions are essential to generate our results.

\subsection{Baseline Setup}

We consider a two-period $(t=0,1)$ two symmetric countries (home $(H)$, foreign $(F)$ ) model. The representative household in each country starts with initial wealth and makes portfolio decisions in period 0 and consumes only in

\footnotetext{
${ }^{7}$ Moreover, when preferences are not restricted to log utility, which is the baseline case of Heathcote and Perri (2007), their model also predicts a high and positive correlation between the real exchange rate and relative equity returns, which as we pointed out earlier, is low in the data.

${ }^{8}$ There is an empirical debate on the existence and relevance of such a shock. See for example, Julliard (2006).

${ }^{9}$ In independent ongoing work, Coeurdacier and Gourinchas (2008) mention government spending shock as an alternative to redistribtive shock. In this paper, we explore the role of government spending thoroughly.
} 
period 1. Two goods, $Y^{H}$ and $Y^{F}$, are endowed to the respective countries in period 1. Each country has a government that only taxes the representative consumer in its country, spends only on domestic goods, and is subject to a budget constraint. The government issues nominal debt in period 0, spends in period 1, and taxes and retires all debt in period 1. We allow for trade in government nominal bonds and claims on the realization of endowments, which we interpret as equity trading.

\subsubsection{Consumers}

For simplicity, in this section, we restrict the agent's preferences as given in assumption 1 below.

Assumption 1: The agents have log utility, no preference bias for domestic goods, and unit elasticity of substitution between domestic and foreign goods.

The domestic representative agent then maximizes the following expected utility (analogous for the foreign agent)

$$
E_{0}\left[\log C_{1}^{H}\right]
$$

where $C_{1}^{H}$ is the composite consumption good and is subject to the following budget constraints in period 0 and 1 , respectively

$$
\begin{gathered}
W_{0}^{H}=B_{0}^{H h}+B_{0}^{H f}+q_{0}^{H} E_{0}^{H h}+q_{0}^{F} E_{0}^{H f} \text { and } \\
C_{1}^{H}+\tau_{1}^{H}=\frac{R_{0}^{H} B_{0}^{H h}}{P_{1}^{H}}+\frac{R_{0}^{F} B_{0}^{H f} Q_{1}}{P_{1}^{F}}+\frac{Y_{1}^{H} E_{0}^{H h} P_{1}^{H h}}{P_{1}^{H}}+\frac{Y_{1}^{F} E_{0}^{H f} Q_{1} P_{1}^{F f}}{P_{1}^{F}}
\end{gathered}
$$

where $E_{0}^{H j}$ is the home agent's holding of claims to endowment $j \epsilon\{h, f\}$ in time $0, B_{0}^{H j}$ is the home agent's holding of nominal bonds in $j$ currency, $q_{0}^{j}$ is the price of a claim on endowment $j$, and $R_{0}^{j}$ is the nominal interest rate on public debt of country $j .{ }^{10}$ Similarly, $P_{1}^{j}$ are the price indices for the respective consumption bundles, $P_{1}^{i j}$ is the price of good $j$ in country $i \epsilon\{h, f\}, Q_{1}$ is the real exchange rate defined as $Q_{1}=\frac{S_{1} P_{1}^{F}}{P_{1}^{H}}$, and $\tau_{1}^{H}$ are taxes. Since this is a twoperiod model, a no-Ponzi condition implies that the total bond holdings of the consumer in period $1, B_{1}^{H h}+B_{1}^{H f}$, should be greater or equal to zero. In writing eqn.(3), we have already imposed the optimality condition, $B_{1}^{H h}+B_{1}^{H f}=0$.

\footnotetext{
${ }^{10}$ Note that in eqn.(2), we normalize the price level in both countries and the nominal exchange rate to 1 in period 0 .
} 
As eqn.(2) makes clear, there is no consumption at $t=0$, but at this date, agents are allowed to trade assets. The home agent starts with initial wealth, $W_{0}^{H}$, which is equal to his asset holdings in period 0 . No consumption or storage technology in period 0 implies that the sum of the wealth of the two agents should be equal to the sum of government debts and the value of the stock of equity. We add an additional restriction that $W_{0}^{H}=W_{0}^{F}=W_{0}$, where $W_{0}$ is a constant. In other words, agents have a symmetric initial endowment of wealth.

In period 1, after the shocks are realized, households consume using their resulting financial income less taxes, as captured by eqn.(3). The composite consumption good is a Cobb-Douglas aggregate of domestic and foreign final goods

$$
C_{1}^{H}=\left(C_{1}^{H h}\right)^{0.5}\left(C_{1}^{H f}\right)^{0.5}
$$

where $C_{1}^{H h}$ and $C_{1}^{H f}$ are home consumption of the domestic and foreign goods. ${ }^{11}$ As is well known, expenditure minimization by the agent will imply the following utility-based aggregate price index at home $P_{1}^{H}=2\left(P_{1}^{H h}\right)^{0.5}\left(P_{1}^{H f}\right)^{0.5}$. The law of one price holds for the two traded goods, implying $P_{1}^{H h}=S_{1} P_{1}^{F h}$, $P_{1}^{H f}=S_{1} P_{1}^{F f}$, and $Q_{1}=\frac{S_{1} P_{1}^{F}}{P_{1}^{H}}=1$. The terms of trade, the ratio of price of exports to imports, facing the domestic economy is defined as $\frac{P_{1}^{H h}}{P_{1}^{H f}}$ or as $\frac{P_{1}^{F h}}{P_{1}^{F f}}$.

The optimality conditions of the home consumer are

$$
\begin{gathered}
E_{0}\left[\frac{R_{0}^{H}}{C_{1}^{H} P_{1}^{H}}\right]=E_{0}\left[\frac{R_{0}^{F}}{C_{1}^{H} P_{1}^{F}} Q_{1}\right]=E_{0}\left[\frac{Y_{1}^{H} P_{1}^{H h}}{q_{0}^{H} C_{1}^{H} P_{1}^{H}}\right]=E_{0}\left[\frac{Y_{1}^{F} Q_{1} P_{1}^{F f}}{q_{0}^{F} C_{1}^{H} P_{1}^{F}}\right] \\
\frac{C_{1}^{H h}}{C_{1}^{H f}}=\frac{P_{1}^{H f}}{P_{1}^{H h}} .
\end{gathered}
$$

The first set of equations show the standard non-arbitrage conditions for the four assets available while the second equation governs the relative demand of the home good with respect to the foreign good.

\footnotetext{
${ }^{11}$ Note the unitary elasticity of substituion between the two goods and no preference bias in consumption.
} 


\subsubsection{Government}

Each government starts in period 0 with a stock of nominal debt (home $\left(B_{0}^{H}\right)$, foreign $\left(B_{0}^{F}\right)$ ) and collects tax on its agent in period 1 (home $\left(\tau_{1}^{H}\right)$, foreign $\left(\tau_{1}^{F}\right)$ ). In period 1 , the home government (analogous for the foreign government) consumes only domestic goods and is subject to the budget constraint

$$
\frac{B_{1}^{H}}{P_{1}^{H}}=\frac{R_{0}^{H} B_{0}^{H}}{P_{1}^{H}}-\tau_{1}^{H}+G_{1}^{H h}\left(\frac{P_{1}^{H h}}{P_{1}^{H}}\right) .
$$

By combining the transversality conditions of the two agents, $B_{1}^{H h}+B_{1}^{H f}=$ 0 and $B_{1}^{F f}+B_{1}^{F h}=0$, it follows that $\frac{B_{1}^{H}}{P_{1}^{H}}+\frac{B_{1}^{F}}{P_{1}^{F}}=0$, that is, the total debt of the two governments in period 1 is equal to zero. Here, we add the assumption that each government pays any outstanding debt in period 1 , that is, $\frac{B_{1}^{H}}{P_{1}^{H}}=\frac{B_{1}^{F}}{P_{1}^{F}}=0$. We think that this is a reasonable additional restriction since other possibilities such as allowing $\frac{B_{1}^{H}}{P_{1}^{H}}$ to be negative and $\frac{B_{1}^{F}}{P_{1}^{F}}$ to be positive would imply that country $H$ would be subsidizing country $F$ government's consumption. This restriction, along with the optimality conditions of the agents, implies, $B_{1}^{H h}=$ $B_{1}^{H f}=B_{1}^{F h}=B_{1}^{F f}=0$. Moreover, we assume that governments start with the same amount of debt, i.e., $B_{0}^{H}=B_{0}^{F}=B_{0}$. From eqn.(2), it follows then that $W_{0}>B_{0}$.

\subsubsection{Market Clearing}

For goods, market clearing conditions are

$$
C_{1}^{H h}+C_{1}^{F h}+G_{1}^{H h}=Y_{1}^{H} \quad C_{1}^{H f}+C_{1}^{F f}+G_{1}^{F f}=Y_{1}^{F} .
$$

In the market for assets notice that there is an outside supply of claims on endowments, which is normalized to 1 , and of nominal bonds issued by the government. Market-clearing conditions are then

$$
\begin{array}{cc}
E_{0}^{H h}+E_{0}^{F h}=1 & E_{0}^{H f}+E_{0}^{F f}=1 \\
B_{0}^{H h}+B_{0}^{F h}=B_{0} & B_{0}^{H f}+B_{0}^{F f}=B_{0} .
\end{array}
$$

\subsubsection{Uncertainty}

We allow for three different types of shocks. First, we assume that a monetary authority controls the price level in period 1, which is a known value in period 
0 plus an error in period 1. That is, $P_{1}^{H}=\bar{P}^{H}+\varepsilon_{1}^{H}$ and $P_{1}^{F}=\bar{P}^{F}+\varepsilon_{1}^{F}$. We motivate this shock as a policy-maker choosing the price level with an error. In section 3 , these policy shocks come from monetary policy through a Taylor-type rule. Second, we allow for endowment shocks $Y_{1}^{H}=\bar{Y}^{H}+\varepsilon_{1}^{Y h}$, $Y_{1}^{F}=\bar{Y}^{f}+\varepsilon_{1}^{Y f}$ and third, we take government $i$ 's expenditure to be an exogenous process, $G_{1}^{H h}=\varepsilon_{1}^{G h}$ and $G_{1}^{F f}=\varepsilon_{1}^{G f}$. All $\varepsilon_{i}^{j}$ are independent with mean 0 and standard deviation $\sigma_{j}$. We normalize the standard deviation of all the shocks to 1 in the analytical sections of the paper and relax this simplification in section 3 .

\subsubsection{Competitive Equilibrium}

An equilibrium is a set of endogenous variables $\Phi_{N}$ that satisfies the consumer's maximization problem, government behavior, and market-clearing conditions, given initial conditions $\Phi_{I}$ and exogenous processes $\Phi_{X}$. The endogenous variable set $\Phi_{N}$ comprises of all consumption allocations, asset allocations, prices, exchange rates, and taxes of both countries, that is, $\Phi_{N}=\left\{C_{1}^{H h}, C_{1}^{H f}, C_{1}^{F f}\right.$, $C_{1}^{F f}, E_{0}^{H h}, E_{0}^{H f}, B_{0}^{H h}, B_{0}^{H f}, E_{0}^{F f}, E_{0}^{F h}, B_{0}^{F f}, B_{0}^{F h}, P_{1}^{H h}, P_{1}^{H f}, P_{1}^{F f}, P_{1}^{F f}, Q_{1}$, $\left.S_{1}, q_{0}, \tau_{1}^{H}, \tau_{1}^{F}\right\}$. The initial conditions set $\Phi_{I}$ is given by the initial amount of government outstanding nominal bonds, pre-determined interests on these bonds, and the initial wealth of each agent, that is, $\Phi_{I}=\left\{B_{0}, W_{0}, R_{0}^{H}, R_{0}^{F}\right\}$. The exogenous variable set $\Phi_{X}$ encompasses the shocks in the economy, that is, $\Phi_{X}=\left\{Y_{1}^{H}, Y_{1}^{F}, G_{1}^{H h}, G_{1}^{F f}, P_{1}^{H}, P_{1}^{F}\right\} .^{12}$

\subsection{Portfolio Holdings}

In this simple set-up we derive optimal portfolio holdings using a guess-andverify method. In our economy, the allocations from the social planner's problem and that from trade of a complete set of state contingent securities coincide for some welfare weights. As is well known, while considering equal welfare weights for these ex-ante identical economies, the allocations under complete markets are given by equating the ratio of marginal utilities of the domestic and foreign agents to the relative price of the domestic and foreign goods. ${ }^{13}$ That is

\footnotetext{
${ }^{12}$ When we allow government consumption to fall on the foreign good in section 2.3, the exogenous processes $G^{H f}$ and $G^{F h}$ should be added to $\Phi_{X}$.

${ }^{13}$ Note that we consider two countries that have the same level of initial wealth.
} 


$$
\frac{C_{1}^{H}}{C_{1}^{F}}=Q_{1}=1
$$

where the second equality holds because of no preference bias for domestic goods in consumption. We guess that in a competitive equilibrium, our model with trade in a limited number of assets, such as equity and bonds, is able to replicate this complete market allocation that would prevail with a full set of state contingent securities. We then back-out equity and bond holdings that indeed support these allocations.

Our main result, given in Proposition 1 below, shows that in this environment, as an optimal outcome, there is complete home bias in nominal government bonds and equity. These portfolio holdings are able to achieve perfect risk-sharing between the countries.

Proposition 1. Given assumption 1, (i) in the presence of nominal, endowment, and government expenditure shocks, if (ii) the government taxes only the domestic agent and (iii) all government expenditure falls on domestic goods, then the agent holds a) only the nominal bonds of her own government and b) only domestic equity.

Proof. Using our market completeness conjecture leads to

$$
\frac{C_{1}^{H}}{C_{1}^{F}}=Q_{1}=1
$$

or

$$
C_{1}^{H}=C_{1}^{F}
$$

Using eqns.(6), (8), and (12) we get

$$
C_{1}^{H h}=C_{1}^{F h}=\frac{1}{2}\left(Y_{1}^{H}-G_{1}^{H h}\right) ; \quad C_{1}^{F f}=C_{1}^{H f}=\frac{1}{2}\left(Y_{1}^{F}-G_{1}^{F f}\right) .
$$

Plugging this back to eqn.(4) yields

$$
C_{1}^{H}=\frac{1}{2}\left(Y_{1}^{H}-G_{1}^{H h}\right)^{\frac{1}{2}}\left(Y_{1}^{F}-G_{1}^{F f}\right)^{\frac{1}{2}}
$$


and to eqn.(6) yields

$\frac{P_{1}^{H h}}{P_{1}^{H f}}=\frac{Y_{1}^{F}-G_{1}^{F f}}{Y_{1}^{H}-G_{1}^{H h}} ; \frac{P_{1}^{H h}}{P_{1}^{H}}=\frac{1}{2}\left(\frac{Y_{1}^{F}-G_{1}^{F f}}{Y_{1}^{H}-G_{1}^{H h}}\right)^{\frac{1}{2}}$ and $\frac{P_{1}^{F f}}{P_{1}^{F}}=\frac{1}{2}\left(\frac{Y_{1}^{H}-G_{1}^{H h}}{Y_{1}^{F}-G_{1}^{F f}}\right)^{\frac{1}{2}}$.

Combining eqns.(3) and (7) leads us to

$C_{1}^{H}+\frac{R_{0}^{H} B_{0}^{H}}{P_{1}^{H}}+G_{1}^{H h} \frac{P_{1}^{H h}}{P_{1}^{H}}=+\frac{R_{0}^{H} B_{0}^{H h}}{P_{1}^{H}}+\frac{R_{0}^{F} B_{0}^{H f}}{P_{1}^{F}}+E_{0}^{H h} \frac{Y_{1}^{H} P_{1}^{H h}}{P_{1}^{H}}+E_{0}^{H f} \frac{Y_{1}^{F} P_{1}^{F f}}{P_{1}^{F}}$.

Using eqns.(14) and (15) in (16) we get

$$
\begin{aligned}
& \frac{1}{2}\left(Y_{1}^{H}-G_{1}^{H h}\right)^{\frac{1}{2}}\left(Y_{1}^{F}-G_{1}^{F f}\right)^{\frac{1}{2}}+\frac{R_{0}^{H} B_{0}^{H}}{P_{1}^{H}}+G_{1}^{H h} \frac{1}{2}\left(\frac{Y_{1}^{F}-G_{1}^{F f}}{Y_{1}^{H}-G_{1}^{H h}}\right)^{\frac{1}{2}}= \\
& +\frac{R_{0}^{H} B_{0}^{H h}}{P_{1}^{H}}+\frac{R_{0}^{F} B_{0}^{H f}}{P_{1}^{F}}+E_{0}^{H h} Y_{1}^{H} \frac{1}{2}\left(\frac{Y_{1}^{F}-G_{1}^{F f}}{Y_{1}^{H}-G_{1}^{H h}}\right)^{\frac{1}{2}}+E_{0}^{H f} Y_{1}^{F} \frac{1}{2}\left(\frac{Y_{1}^{H}-G_{1}^{H h}}{Y_{1}^{F}-G_{1}^{F f}}\right)^{\frac{1}{2}} .
\end{aligned}
$$

The market completeness condition is then satisfied only if we can find $E_{0}^{H h}, E_{0}^{H f}, B_{0}^{H h}$, and $B_{0}^{H f}$ that satisfy the above equation for all realizations of shocks and are not contingent on them. The unique asset allocation that fulfills this requirement is $B_{0}^{H h}=B_{0}^{H}, B_{0}^{H f}=0, E_{0}^{H h}=1$ and $E_{0}^{H f}=0$. Competitive equilibrium prices that support these consumption and asset allocations are those that satisfy $q_{0}^{H}=q_{0}^{F}=W_{0}-B_{0}$ and $R_{0}^{H}=R_{0}^{F}$ and eqn. (5).

Complete home bond bias is an optimal outcome because it provides insurance against nominal shocks and the resulting movement in taxes. To see this, ignoring government spending shocks for now, notice from eqn.(7) and $\frac{B_{1}^{H}}{P_{1}^{H}}=0$ that there is a clear negative relationship between the price level and the taxes at home in period 1. This implies a positive correlation between returns on domestic bonds and domestic taxation. Then from eqn.(3) and ignoring equity positions for now, it is clear that by holding primarily domestic government bonds, the agent will be able to hedge against the movement in taxation that results from a shock to the domestic price level. In particular, holding foreign nominal bonds will lead to exposure to foreign price shocks without being compensated by the resulting tax movement. We want to emphasize that the only requirements for our result are some uncertainty with respect to the price level, as well as the fact that the government taxes only her citizen 
Complete home equity bias is an optimal outcome because it provides insurance against government spending shocks and the resulting movement in taxes. When a domestic government spending shock hits, domestic taxes have to increase to fulfill the budget constraint. Given this increase in taxes, the agents would like to hold more of an asset that has a higher rate of return. When government spending falls only on the domestic good, it increases the relative price of the domestic good compared to the foreign good. This can be seen clearly from the expression $\frac{P_{1}^{H h}}{P_{1}^{H f}}=\frac{Y_{1}^{F}-G_{1}^{F f}}{Y_{1}^{H}-G_{1}^{H h}}$. This implies that the relative rates of return on domestic equity are higher, since the difference in returns between domestic and foreign equity is given by $\frac{Y_{1}^{H} P_{1}^{H h}-Y_{1}^{F} P_{1}^{H f}}{P_{1}^{H}}$. Hence, optimal equity portfolios are biased domestically.

Note that as shown in Cole and Obstfeld (1991), with assumption 1, equity allocation with only endowments shocks is indeterminate, as all possible combinations of equity allocations achieve perfect risk sharing. This is because the terms of trade movement perfectly pools all risk arising from endowment shocks, regardless of equity holdings. ${ }^{14}$ Here, we introduce government expenditure shocks in addition to endowment shocks, and have shown that this result can be overturned, and that there is a specific allocation for equity which achieves the complete market allocation. In fact when government spending falls only on domestic goods, it leads to a complete home bias in equity holdings. Finally, we want to emphasize that our proof makes clear that equity and bond portfolio decisions are separable as positions on these assets are taken to insure against different shocks. Thus, if we had a set-up where there is trade only in bonds and only nominal shocks, optimal bond positions would imply complete home bias as in proposition 1. Similarly, if we had a set-up where there is trade only in equity with government spending and endowment shocks, optimal equity positions would imply complete home bias as in proposition 1 .

\subsection{Model Extensions}

To assess the robustness of our results, we now allow for general preferences and relax the simplifying assumption on government spending we made above. The

\footnotetext{
${ }^{14}$ To see the Cole and Obstfeld (1991) indeterminacy result with only endowment shocks, note that in that case, the condition to be satisfied reduces to: $\frac{1}{2} Y_{1}^{H \frac{1}{2}} Y_{1}^{F \frac{1}{2}}+\frac{R_{0}^{H} B_{0}^{H}}{P_{1}^{H}}=$ $\frac{R_{0}^{H} B_{H}^{H h}}{P_{1}^{H}}+\frac{R_{0}^{F} B_{P}^{H f}}{P_{1}^{F}}+E_{0}^{H h} Y_{1}^{H} \frac{1}{2}\left(\frac{Y_{1}^{F}}{Y_{1}^{H}}\right)^{\frac{1}{2}}+E_{0}^{H f} Y_{1}^{F} \frac{1}{2}\left(\frac{Y_{1}^{H}}{Y_{1}^{F}}\right)^{\frac{1}{2}}$. This condition can be satisfied for: $B_{0}^{H h}=B_{0}^{H}, B_{0}^{H f}=0$, and any value of $E_{0}^{H h}$.
} 
representative consumer maximizes

$$
E_{0}\left[\frac{\left(C_{1}^{H}\right)^{1-\sigma}}{1-\sigma}\right] \quad \sigma>0
$$

where $C_{1}^{H}$ is now defined as

$$
C_{1}^{H}=\left[a^{\frac{1}{\eta}}\left(C_{1}^{H h}\right)^{\frac{\eta-1}{\eta}}+(1-a)^{\frac{1}{\eta}}\left(C_{1}^{H f}\right)^{\frac{\eta-1}{\eta}}\right]^{\frac{\eta}{\eta-1}} \eta>0
$$

where $\eta$ is the elasticity of substitution between home and foreign goods and $a$ denotes the relative preference of domestic over foreign goods, with $a>0.5$ implying home consumption bias in preferences. Expenditure minimization by the agent will imply the following utility-based aggregate price index at home $P_{1}^{H}=\left[a\left(P_{1}^{H h}\right)^{1-\eta}+(1-a)\left(P_{1}^{H f}\right)^{1-\eta}\right]^{\frac{1}{1-\eta}}$. Moreover, as a generalization, we specify that the government spends a constant fraction of its total consumption on domestic goods as given by $G_{1}^{H h}=x G_{1}^{H f}$ and $G_{1}^{F f}=x G_{1}^{F h}$ where $x>0$. This means that if $x>1$, government consumption is biased towards the domestic good. ${ }^{15}$

\subsubsection{Complete Markets}

We first consider a set-up with only government spending and nominal shocks, which implies complete markets upto a first-order approximation. As shown extensively in the literature starting with Lucas (1982), in an environment with idiosyncratic shocks to endowment and no consumption bias in preferences, the agent's optimal allocation for claims on the realization of these endowments would seek complete diversification of his country-specific risk. Here we show that this result can be overturned, and substantial home equity bias can be generated as an optimal portfolio decision, when stochastic government expenditure is biased towards domestic goods.

In the appendix in proposition 2 we show that domestic holdings of home equity, denoted here for simplicity by $\theta$, are given by

$$
\theta=\frac{1}{2}+\frac{1}{2}(2 a-1)\left[\frac{1+x}{x-1}\left(\frac{2 a-1}{\sigma}-\frac{4 \eta a(a-1)}{2 a-1}\right)+1-\frac{1}{\sigma}\right]
$$

\footnotetext{
${ }^{15}$ The exogenous processes for government expenditures are then $G_{1}^{H}=G_{1}^{H h} \frac{P_{1}^{H h}}{P_{1}^{H}}+$ $G_{1}^{H f} \frac{P_{1}^{H f}}{P_{1}^{H}}=\varepsilon_{1}^{G h}$ and $G_{1}^{F}=G_{1}^{F h} \frac{P_{1}^{F h}}{P_{1}^{F}}+G_{1}^{F f} \frac{P_{1}^{F f}}{P_{1}^{F}}=\varepsilon_{1}^{G f}$.
} 
and that the agent holds only domestic nominal bonds. ${ }^{16}$ Notice that for $a=0.5$, eqn.(18) reduces to

$$
\theta=\frac{1}{2}\left(\frac{\eta(1+x)}{x-1}+1\right)
$$

In this case, we also show in proposition 2 that eqn.(19) implies home equity bias whenever $x>1$. For a general value of $a$ using eqn.(18), we find numerically that once we assume $\sigma>0.2,{ }^{17} x>1$ is still a sufficient condition for home bias in equity, regardless of the value of $\eta$.

What is the intuition for this result? As before, when a positive domestic government spending shock hits, domestic taxes have to increase to fulfill the budget constraint. Given this increase in taxes, the agents would like to hold more of an asset that has a higher rate of return. When government spending falls relatively more on the domestic good, since it is effectively a positive demand shock, it increases the relative price of the domestic good compared to the foreign good, $\hat{P}_{1}^{H h}-\hat{P}_{1}^{H f}$. Since the relative rate of return on domestic equity is given by $\left(\hat{Y}_{1}^{H}+\hat{P}_{1}^{H h}-\hat{P}_{1}^{H}\right)-\left(\hat{Y}_{1}^{F}+\hat{P}_{1}^{H f}-\hat{P}_{1}^{H}\right)=\hat{P}_{1}^{H h}-\hat{P}_{1}^{H f}$, it is now higher than before. Hence, optimal portfolios are biased domestically as it provides a hedge against taxation resulting from government expenditure shocks.

Notice that $\theta$ is a decreasing function of $x$, if $x>1$. The intuition is clear: in response to a government expenditure shock, $x$ slightly above 1 would make the relative returns on domestic equity only slightly higher and so a huge asset position is needed to hedge against the taxation movement, which is invariant to the composition of government expenditure. Finally, by comparing eqn.(19) with eqn.(18), we see that there is greater home bias in equity holdings when $a>0.5$ compared to $a=0.5$, whenever $\eta$ is lower than 1 . The intuition for this result is the following. With $a>0.5$, there is an additional channel for government spending to affect equity holdings since given a government spending shock, the real exchange rate appreciates leading to a higher price for the domestic good. Now because the domestic agent is more biased towards the domestic good, which has become more expensive relative to the foreign good, and she has relatively inelastic demand as $\eta<1$, she needs to hold more

\footnotetext{
${ }^{16}$ Note that we are considering government spending and nominal shocks while excluding endowment shocks.

${ }^{17}$ The literature, for example, Coeurdacier et al (2007), usually assumes either log-utility or $\sigma>1$.
} 
of the asset with higher returns. With government spending falling relatively more on domestic good, for the same reasons described before, domestic equity is precisely such an asset.

\subsubsection{Incomplete Markets}

We have used market completeness so far to help us show our mechanisms clearly. A necessary robustness check of our results however, is market incompleteness since empirical evidence suggests that there is imperfect risk sharing in international financial markets. ${ }^{18}$ We take up this task by allowing for nominal, government spending, and endowment shocks with trade in nominal bonds and equities. This will imply that markets are incomplete, even up to a first order approximation. Moreover, there is a clear trade-off in the problem of equity allocation: while endowment shocks call for full diversification, the home-biased government expenditure shock leads to home bias in equity.

In the appendix, we show using recently developed techniques, that for $a=0.5$, the home equity allocation, $\theta$, is given by

$$
\theta=\frac{1}{2}+\frac{1}{2} \frac{\eta\left(x^{2}-1\right)}{(\eta-1)^{2}(1+x)^{2}+2(1-x)^{2}} .
$$

The optimal nominal bonds allocation is $B_{0}^{H h}=B_{0}^{H}$, that is, full home bias once again. ${ }^{19}$ The first term in eqn.(20), which leads to $\theta=\frac{1}{2}$, reflects the hedging motive against idiosyncratic endowment shocks. The second term reflects hedging against government spending shocks. When $x=1$, government spending shock does not affect the terms of trade, and hence this term is zero and optimal equity holdings are fully diversified. In this situation, we have a generalized version of the Lucas (1982) model with government shocks.

When $x>1$ however, the second term is positive, leading to a home bias in equity holdings. The expression makes it clear that this result does not

\footnotetext{
${ }^{18}$ See for example, Corsetti et al (2008). Complete market models predict perfect comovement between the real exchange rate and relative marginal utilities between countries. In the absence of preferenc shocks, this implies a perfect comovement between the real exchange rate and relative consumption bewtween the countries. This implication is strongly rejected empirically. This is also known as the Backus-Smith puzzle in the literature.

${ }^{19}$ Note that even here we are normalizing the variance of all the shocks to unity. Of course, with incomplete markets, the relative variances of the shocks plays a role in portfolio holdings. But, we have abstracted from this issue here to keep the presentation cleaner and focused and to allow a direct comparison with the complete markets case analyzed earlier. In the quantitative exercise in section 3 , the variances of the different shocks will be calibrated from data.
} 
depend on the value of $\eta$. In fig.1, we plot the value of $\theta$ for different values of $\eta$. Notice that as $x$ increases above 1 , there is a trade off between the shocks: while government expenditures shocks push the allocations to start high and to decrease monotonically, endowment shocks push for diversification. The sum of these effects leads to an initial increase and subsequent decrease of home bias in equity allocation, as $x$ increases.

In the case of incomplete markets and any value for $\sigma$ and $a>0.5$, we show the system of equations to be solved in the appendix. The final analytical solution for portfolio holdings turns out to be cumbersome and we resort to numerical solutions to find the condition for home bias in equity. We are particularly interested on how these allocations depend on $x$, the fraction of government consumption on domestic goods and the degree of consumers' home bias, $\frac{a}{1-a}$. A robust result is that for reasonable values of $\sigma, x$ roughly greater than $\frac{a}{1-a}$ again generates home equity bias, regardless of the value of $\eta$. In the appendix, we plot the results for for $\sigma=1.5$ and for different values of $a$ and $\eta$. It is clear that for all $x>\frac{a}{1-a}$, the home bias on equity is high. This approximate bound $x>\frac{a}{1-a}$ can be made exact in the case of log-utility, as shown in proposition 3 in the appendix.

We see that here the change from the case with complete markets, or incomplete markets but with $a=0.5$, is that the necessary and sufficient condition to generate home bias in equity is now $x>\frac{a}{1-a}$ as opposed to $x>1$. In other words, now we need the government to be more biased than the consumer in order to generate home bias in equity, but the result is still independent of the value of $\eta$. Why does the case with incomplete markets and $a>0.5$ require more bias in government spending compared to the cases we have analyzed before? The fundamental reason is that with incomplete markets and $a>0.5$, the real exchange rate moves in response to the shocks, and hence there arises a hedging motive against this real exchange rate movement. In essence, since $\frac{a}{1-a}$ determines the extent of agent's bias in consumption and the resulting role for real exchange rate hedging, $x>\frac{a}{1-a}$ is needed to ensure that the terms of trade movement due to government shocks counteracts the real exchange rate movement. Another important result in this case is that due to market incompleteness, monetary policy affects the terms of trade and has real effects even with log utility. As a result, we show in the appendix that while there is still substantial home bias in bonds, the agent does not hold only domestic bonds as it can improve insurance by holding some foreign 
bonds.

In conclusion, therefore, we have shown that in a variety of settings, complete or incomplete markets, log utility or general CRRA utility, home consumption bias or not, a sufficient condition for home bias in equity is that the government spending is more biased towards domestic goods as compared to the consumer. We have also shown that the result of home bias in bonds is valid when we allow for the aforementioned extensions. Most importantly, we generate home equity bias without depending on the value of $\eta$, the elasticity of substitution between domestic and foreign goods. ${ }^{20}$

\subsection{Literature}

We now briefly discuss related literature that uses a similar model environment as the one we considered above. We are not aware of any other papers that has shown equilibrium government debt portfolios to be predominantly domestic. Devereux and Sutherland (2006) have an endowment economy model with nominal bonds, but the bonds are inside assets in net zero supply. ${ }^{21}$ In their model, where nominal demand is exogenous, a positive domestic endowment shock has a negative effect only on the domestic price level. Therefore, domestic bond returns are high precisely when output is high. In order to hedge against the endowment shock, agents therefore, take a short position in domestic nominal bonds. In our model, in contrast, a domestic endowment shock affects both the domestic and foreign price levels by the same amount. Thus, government debt positions cannot be used to hedge against output risk. In fact, with only endowment shocks, domestic and foreign government bonds are perfect substitutes. Nominal bonds are therefore used to hedge against idiosyncratic country specific price level shocks, which as we have explained before, create a positive correlation between taxes and returns on domestic bonds.

For home equity bias, the literature using an endowment economy model is fairly large. First, as explained in detail in Obstfeld (2006) and Coeurdacier

\footnotetext{
${ }^{20}$ We have also checked that all our results are robust to other model extensions such as allowing for inflation indexed bonds and for a part of government spending to be endogenous. The results are available on request from the authors.

${ }^{21}$ Engel and Matsumoto (2009) present a model where there is trade in forward contracts on nominal foreign exchange. This is essentially the same as allowing for trades in inside nominal bonds denominated in different currencies. Again, they do not consider government (outside) nominal bonds and the associated optimal portfolio holdings, which is the focus of our paper.
} 
et al (2007), the previous literature can generate home bias in equity only by starting with the assumption that $a>0.5$. In this paper, we generate equity home bias even when $a=0.5$. Second, even after assuming $a>0.5$, for reasonable degree of risk aversion, the mechanism requires that $\eta$, the elasticity of substitution between domestic and foreign goods, be (approximately) less than $1 .^{22}$ There is a great deal of uncertainty in the empirical literature regarding the value of $\eta$, and most estimates put it above $1 .^{23}$ Given this, we view the fact that our result is independent of the value of $\eta$ to be a significant strength of our proposed mechanism. To drive home the difference from the previous literature, table 2 compares results for equity holdings only with endowment shocks, with those in our model with government spending shocks and endowment shocks and $a>0.5$, that is, section 2.3.2. The results are for $\sigma=1.5$. The table makes clear that the introduction of a government spending shock that is biased towards domestic good leads to home bias in equity, even when $\eta>1$. The previous literature, on the other hand, relies on $\eta<1$, which is outside the range of most empirical estimates.

Moreover, the previous literature's mechanism which generates home equity bias in response to endowment shocks by relying on $a>0.5$ and $\eta<$ 1, implies a strong positive correlation between the real exchange rates and equity returns. This is because equity positions are used to hedge against real exchange rate risk. As van Wincoop and Warnock (2006) find however, this correlation is close to 0 in the data. In our set up, when $a=0.5$, the real exchange rate upto first order is zero, and there is no correlation between the real exchange rate and relative equity returns. We view this as another strength of our mechanism since it clearly shows that equity bias is not a result of hedging against real exchange rate risk. Even when there is home consumption bias in preferences, and hence real exchange rate movement, since we have both government spending shocks and endowment shocks, the correlation between real exchange rates and equity returns is not pinned down to be high and positive. For example, when we compute $\operatorname{Cov}_{0}$ (relative equity returns $\left._{1}, \hat{Q}_{1}\right) / \operatorname{Var}_{0}\left(\right.$ relative equity returns ${ }_{1}$ ) in the model of section 2.3 .2 , for $\eta=1.2$ and $x=4$, it is 0.0855 and for $\eta=1.5$ and $x=4$, it is $-0.0450 .^{24}$

\footnotetext{
${ }^{22}$ In our set-up with nominal and endowment shocks, bond holdings will be completely domestic, while equity holdings will be given by $\frac{1}{2}\left[1+\frac{(2 a-1)(\rho-1)}{-\rho+4 \eta \rho(1-a)+(2 a-1)^{2}}\right]$. Notice that equity holdings are fully diversified if $a=0.5$ or $\rho=1$.

${ }^{23}$ See Coeurdacier et al (2007) and citations therein.

${ }^{24}$ Benigno and Nistico (2012) argue that focusing on this static correlation between real
} 


\section{Dynamic Model with Production}

\subsection{Setup}

In this section we present a fully dynamic infinite-horizon model with production so that we can undertake a realistic quantitative exercise. We consider two symmetric production economies, each populated by a representative agent. Each country specializes in the production of one tradable final good. Within each country, the agent consumes a domestically produced good and an imported good. Both of the tradable goods are produced in differentiated brands by a continuum of monopolistically competitive firms of measure 1. A brand of a given good is an imperfect substitute for all other brands of that good. Firms use only labor, that is supplied competitively and is immobile between countries, in their production process. For simplicity, there are no intermediate and non-tradable goods in the model. Furthermore, prices are fully flexible.

In each country, there is also a government that supplies one period non state-contingent nominal bonds and taxes the labor income of the representative agent and profits of the firm. The government conducts monetary policy using a interest rate rule and fiscal policy using a rule for taxes. Agents in each country can trade claims to aggregate profits of the firms and hold domestic and foreign bonds with returns denominated in the respective currencies. Since there are three sources of aggregate uncertainty in the model: productivity shocks, monetary shocks, and government spending shocks, and asset trade is limited to only equities and nominal bonds, markets are incomplete and therefore, risk-sharing of the country-specific shocks is imperfect.

\subsubsection{Consumer}

A representative agent at home maximizes the expected present discounted value of utility

$$
E_{t} \sum_{t=0}^{\infty} \beta^{t}\left[\frac{\left(C_{t}^{H}\right)^{1-\sigma}}{1-\sigma}-\lambda \frac{\left(L_{t}^{H}\right)^{1+\nu}}{1+\nu}\right] \quad 0<\beta<1, \sigma>0, \nu>0, \lambda>0
$$

where $C_{t}^{H}$ is the composite domestic consumption good and $L_{t}^{H}$ is domestic labor supply. The agent is subject to the period budget constraint

exchange rates and equity returns could be misleading in a dynamic context. 


$$
\begin{gathered}
C_{t}^{H}+\frac{B_{t}^{H h}}{P_{t}^{H}}+\frac{B_{t}^{H f}}{P_{t}^{F}} Q_{t}+q_{t}^{H} E_{t}^{H h}+q_{t}^{F} E_{t}^{H f} Q_{t}=\left(1-\tau_{t}^{L}\right) w_{t}^{H} L_{t}^{H} \\
+\frac{R_{t-1}^{H} B_{t-1}^{H h}}{P_{t}^{H}}+\frac{R_{t-1}^{F} B_{t-1}^{H f}}{P_{t}^{F}} Q_{t}+\left(q_{t}^{H}+\Pi_{t}^{H}\right) E_{t-1}^{H h}+\left(q_{t}^{F}+\Pi_{t}^{F}\right) Q_{t} E_{t-1}^{H f}
\end{gathered}
$$

where $B_{t-1}^{H h}, B_{t-1}^{H f}, E_{t-1}^{H h}$, and $E_{t-1}^{H f}$ are holdings of domestic nominal bonds, foreign nominal bonds, claims to aggregate after-tax profits of domestic firms, and claims to aggregate after-tax profits of foreign firms purchased in period $t-1$ to be brought into period $t .^{25}$

Moreover, $P_{t}^{H}$ is the aggregate domestic price level, $P_{t}^{F}$ is the aggregate foreign price level, $Q_{t}$ is the real exchange rate, $q_{t}^{H}$ is the (real) price of one unit of claim to domestic profits, $q_{t}^{F}$ is the (real) price of one unit of claim to foreign endowment, $\Pi_{t}^{H}$ is after-tax aggregate real profits of domestic firms, $\Pi_{t}^{F}$ is after-tax aggregate real profits of foreign firms, $R_{t-1}^{H}$ is the nominal interest rate on domestic bonds accruing to bond holdings in period $t$ (but known in period $t-1), R_{t-1}^{F}$ is the nominal interest rate on foreign bonds accruing to bond holdings in period $t$ (but known in period $t-1$ ), $\tau_{t}^{L}$ is the rate of labor income tax, and $w_{t}^{H}$ is the real wage at home. For future purposes, define real wealth of the home agent $W_{t}^{H}$ as

$$
W_{t}^{H}=\frac{B_{t}^{H h}}{P_{t}^{H}}+\frac{B_{t}^{H f}}{P_{t}^{F}} Q_{t}+q_{t}^{H} E_{t}^{H h}+q_{t}^{F} E_{t}^{H f} Q_{t} .
$$

The composite consumption good $C_{t}^{H}$ is a CES aggregate of domestic $C_{t}^{H h}$ and foreign $C_{t}^{H f}$ final goods as defined in section 2.3. The home consumption good $C_{t}^{H h}$ is produced in differentiated brands $c_{t}^{H h}$ by a continuum of monopolistically competitive home firms indexed $j$ and of measure 1 , and is defined as

$$
C_{t}^{H h}=\left[\int_{0}^{1} c_{t}^{H h}(j)^{\frac{\theta-1}{\theta}} d j\right]^{\frac{\theta}{\theta-1}} \theta>1
$$

where the elasticity of substitution among the brands is given by $\theta$. Similarly, the foreign consumption good $C_{t}^{H f}$ is produced in differentiated brands $c_{t}^{H f}$

\footnotetext{
${ }^{25}$ We follow Devereux and Sutherland (2006), Engel and Matsumoto (2009), and Benigno and Nistico (2012), among others, in modelling equities this way: as claims on profits of monopolistically competitive firms.
} 
by a continuum of monopolistically competitive foreign firms indexed $f$ and of measure 1 , and is defined as

$$
C_{t}^{H f}=\left[\int_{0}^{1} c_{t}^{H f}(f)^{\frac{\theta-1}{\theta}} d f\right]^{\frac{\theta}{\theta-1}}
$$

where the elasticity of substitution among the brands is given by $\theta$.

As is well known, expenditure minimization by the agent will imply a utility-based aggregate price index at home, $P_{t}^{H}$, exactly as in section 2.3. Expenditure minimization will also imply the following domestic price level of the home consumption good $P_{t}^{H h}=\left[\int_{0}^{1} p_{t}^{H h}(j)^{1-\theta} d j\right]^{\frac{1}{1-\theta}}$, where $p_{t}^{H h}(j)$ is the domestic price level of brand $j$ of the domestic good, and the following domestic price level of the foreign consumption good $P_{t}^{H f}=\left[\int_{0}^{1} p_{t}^{H f}(f)^{1-\theta} d f\right]^{\frac{1}{1-\theta}}$, where $p_{t}^{H f}(f)$ is the domestic price level of brand $f$ of the foreign good.

Similarly, given the definition of the consumption goods and the price levels, manipulation of the demand curves at the brand level gives

$$
\frac{c_{t}^{H h}(j)}{C_{t}^{H h}}=\left(\frac{p_{t}^{H h}(j)}{P_{t}^{H h}}\right)^{-\theta} \quad \frac{c_{t}^{H f}(j)}{C_{t}^{H f}}=\left(\frac{p_{t}^{H f}(j)}{P_{t}^{H f}}\right)^{-\theta} .
$$

The law of one price holds among the tradable brands and hence we have

$$
p_{t}^{H h}(j)=S_{t} p_{t}^{F h}(j) \quad p_{t}^{H f}(f)=S_{t} p_{t}^{F f}(f)
$$

where $p_{t}^{F h}(j)$ and $p_{t}^{F f}(f)$ are the foreign price level of price of the brand $j$ of the domestic good and brand $f$ of the foreign good.

Given the definition of the consumption indices and the price indices resulting from expenditure minimization, the optimization problem of the consumer, that is maximizing eqn.(21) with respect to $C_{t}^{H}, B_{t}^{H h}, B_{t}^{H f}, E_{t}^{H h}, E_{t}^{H f}$, and $L_{t}^{H}$, subject to eqn.(22), results in

$$
\begin{gathered}
\frac{1}{\left(C_{t}^{H}\right)^{\sigma}}=E_{t}\left[\frac{\beta P_{t}^{H} R_{t}^{H}}{\left(C_{t+1}^{H}\right)^{\sigma} P_{t+1}^{H}}\right]=E_{t}\left[\frac{\beta P_{t}^{F} R_{t}^{F} Q_{t+1}}{\left(C_{t+1}^{H}\right)^{\sigma} P_{t+1}^{F} Q_{t}}\right], \\
\frac{1}{\left(C_{t}^{H}\right)^{\sigma}}=E_{t}\left[\frac{\beta\left(q_{t+1}^{H}+\Pi_{t+1}^{H}\right)}{\left(C_{t+1}^{H}\right)^{\sigma} q_{t}^{H}}\right]=E_{t}\left[\frac{\beta\left(q_{t+1}^{F}+\Pi_{t+1}^{F}\right) Q_{t+1}}{\left(C_{t+1}^{H}\right)^{\sigma} q_{t}^{F} Q_{t}}\right] \\
\lambda\left(L_{t}^{H}\right)^{\nu}=\left(C_{t}^{H}\right)^{-\sigma}\left(1-\tau_{t}^{L}\right) w_{t}^{H} .
\end{gathered}
$$


Eqns.(27)-(28) are the familiar euler equations with respect to the four assets that are available while eqn.(29) determines labor supply decisions of the agent by equating the marginal rate of substitution between leisure and consumption with after tax real wage. The budget constraint and the optimization problem of the foreign representative agent is entirely analogous and is not presented here to conserve space.

\subsubsection{Firms}

Each brand $j$ of the domestic good is produced by a single home firm $j$ using the following linear production function

$$
y_{t}^{H}(j)=A_{t}^{H} l_{t}^{H}(j)
$$

where $y_{t}^{H}(j)$ is the domestic output of brand $j, A_{t}^{H}$ is the country-specific productivity shock that follows an exogenous process, and $l_{t}^{H}(j)$ is the labor demand by firm $j$. Firms hire labor in a competitive market taking the wage as given and the labor used is homogenous across all firms $j$. The firms are identical except for the fact that they produce differentiated brands for the same good. The process for productivity is given by $\log A_{t}^{H}=\rho_{A} \log A_{t-1}^{H}+\epsilon_{a, t}$.

Firm $j$ maximizes real profits, that is revenue less labor costs, given by

$$
\frac{p_{t}^{H h}(j) y_{t}^{H}(j)}{P_{t}^{H}}-w_{t}^{H} l_{t}^{H}(j)
$$

subject to eqn.(30) and eqn.(25), leading to the familiar pricing equation

$$
p_{t}^{H h}(j)=\frac{\theta}{\theta-1} P_{t}^{H}\left(\frac{w_{t}^{H}}{A_{t}^{H}}\right)
$$

where monopolistically competitive firms charge a price that is a mark-up times the nominal marginal cost.

The aggregate after tax real profits of the firms in the domestic economy can be written as

$$
\Pi_{t}^{H}=\left(1-\tau_{t}^{\pi}\right)\left(P_{t}^{H h}-\frac{w_{t}^{H}}{A_{t}^{H}} P_{t}^{H}\right) \frac{Y_{t}^{H}}{P_{t}^{H}}
$$

and the optimization decision of the individual domestic firms gives

$$
\frac{P_{t}^{H h}}{P_{t}^{H}}=\frac{\theta}{\theta-1} \frac{w_{t}^{H}}{A_{t}^{H}}
$$


The optimization problem of the foreign firms is entirely analogous and is not presented here to conserve space.

\subsubsection{Government}

The home government faces the following period budget constraint

$$
\frac{B_{t}^{H}}{P_{t}^{H}}=\frac{R_{t-1}^{H} B_{t-1}^{H}}{P_{t}^{H}}-\tau_{t}^{L} w_{t}^{H} L_{t}^{H}-\tau_{t}^{\pi}\left(P_{t}^{H h}-\frac{w_{t}^{H}}{A_{t}^{H}} P_{t}^{H}\right) \frac{Y_{t}^{H}}{P_{t}^{H}}+G_{t}^{H h} \frac{P_{t}^{H h}}{P_{t}^{H}}+G_{t}^{H f} \frac{P_{t}^{H f}}{P_{t}^{H}}
$$

where $B_{t}^{H}$ is total nominal debt issued by the home government in period $t$ and $G_{t}^{H h}$ and $G_{t}^{H f}$ respectively are the home government's spending on domestic and foreign good. ${ }^{26}$ The ratio of labor tax revenue vs. profit tax revenue is for simplicity, constant

$$
\tau_{t}^{L} w_{t}^{H} L_{t}^{H}=y\left[\tau_{t}^{\pi}\left(P_{t}^{H h}-\frac{w_{t}^{H}}{A_{t}^{H}} P_{t}^{H}\right) \frac{Y_{t}^{H}}{P_{t}^{H}}\right]
$$

where $y$ is a parameter of our model.

We assume here that government spending over the differentiated brands of the domestic and foreign goods is defined in the same way as for the consumer with the same elasticity of substitution over the brands. That is,

$$
G_{t}^{H h}=\left[\int_{0}^{1} g_{t}^{H h}(j)^{\frac{\theta-1}{\theta}} d j\right]^{\frac{\theta}{\theta-1}} \quad G_{t}^{H f}=\left[\int_{0}^{1} g_{t}^{H f}(f)^{\frac{\theta-1}{\theta}} d f\right]^{\frac{\theta}{\theta-1}} .
$$

The ratio of government spending over domestic vs. foreign good is for simplicity, constant

$$
G_{t}^{H h}=x G_{t}^{H f}
$$

where $x$ is a parameter of our model. Government spending follows an exogenous process

$$
G_{t}^{H}=G_{t}^{F h}\left(\frac{P_{t}^{F h}}{P_{t}^{F} Q_{t}}\right)+G_{t}^{F f}\left(\frac{P_{t}^{F f}}{P_{t}^{F}}\right)=\rho_{G} G_{t-1}^{H h}+\epsilon_{g, t} .
$$

\footnotetext{
${ }^{26}$ Notice we have no lump-sum taxes and allow the government to tax both the labor income of the home agent and the profits of home firms so that the model can be taken to the data realistically.
} 
In this paper, we do not consider explicit optimal government policy and use simple rules as descriptions of government policy. The government conducts monetary policy using a interest rate rule given by

$$
R_{t}^{H}=\gamma_{0}\left(P_{t}^{H} / P_{t-1}^{H}\right)^{\gamma} \exp \left(\epsilon_{r, t}^{H}\right)
$$

where the interest rate shock follows the exogenous process $\log \epsilon_{r, t}^{H}=\rho_{R} \log \epsilon_{r, t-1}^{H}$ $+e_{r, t}$ and fiscal policy using a rule for total tax revenue responding to real value of debt

$$
\tau_{t}^{L} w_{t}^{H} L_{t}^{H}+\tau_{t}^{\pi}\left(P_{t}^{H h}-\frac{w_{t}^{H}}{A_{t}^{H}} P_{t}^{H}\right) \frac{Y_{t}^{H}}{P_{t}^{H}}=\phi_{0}\left(\frac{B_{t}^{H}}{P_{t}^{H}}\right)^{\phi} .
$$

Again, the foreign government's description is completely analogous and symmetric. $^{27}$

\subsubsection{Market Clearing}

Market clearing for goods implies

$$
\begin{aligned}
c_{t}^{H h}(j)+c_{t}^{F h}(j)+g_{t}^{H h}(j)+g_{t}^{F h}(j) & =A_{t}^{H} l_{t}^{H}(j) \\
c_{t}^{F f}(f)+c_{t}^{H f}(f)+g_{t}^{H f}(f)+g_{t}^{F f}(f) & =A_{t}^{F} l_{t}^{F}(j) .
\end{aligned}
$$

Similarly, market clearing for assets implies

$$
\begin{aligned}
& E_{t}^{H h}+E_{t}^{F h}=1 \quad E_{t}^{H f}+E_{t}^{F f}=1 \\
& B_{t}^{H h}+B_{t}^{F h}=B_{t}^{H} \quad B_{t}^{H f}+B_{t}^{F f}=B_{t}^{F}
\end{aligned}
$$

and total labor demand by firms equaling labor supply implies

$$
\int_{0}^{1} l_{t}^{H}(j) d j=L_{t}^{H}
$$

\footnotetext{
${ }^{27}$ Here we assume that taxes react to current levels of real debt. This is just for expositional convenience and does not affect our results. We also experimented with alternate tax rules where current taxes depend on different weighted sums of lagged levels of government debt, thereby keeping the government solvent without fiscal policy determining the price level. Quantitative results were very similar. In addition, in the special case where all taxes are lump-sum, a numerical exercise showed that all that matters for portfolio allocation is how the present value of life-time taxes adjusts to innovations in the real value of debt.
} 


\subsubsection{Competitive Equilibrium}

An equilibrium is a set of quantities, $c_{t}^{H h}(j), \quad c_{t}^{H f}(j), c_{t}^{F h}(j), \quad c_{t}^{F f}(j), l_{t}^{H}(j)$, $l_{t}^{F}(j), E_{t}^{H h}, E_{t}^{H f}, B_{t}^{H h}, B_{t}^{H f}, B_{t}^{H}, E_{t}^{F f}, E_{t}^{F h}, B_{t}^{F f}, B_{t}^{F h}, B_{t}^{F}, \tau_{t}^{L}, \tau_{t}^{\pi}$ prices, $p_{t}^{H h}(j), p_{t}^{H f}(j), p_{t}^{F f}(j), p_{t}^{F f}(j), Q_{t}, S_{t}, q_{t}^{H}, q_{t}^{F}, w_{t}^{H}, w_{t}^{F}, R_{t}^{H}, R_{t}^{F}$, and exogenous processes $A_{t}^{H}(j), A_{t}^{F}(j), G_{t}^{H}, G_{t}^{F}, \epsilon_{r, t}, \epsilon_{r, t}$ for all $t \geqslant 0$, that satisfy eqns.(22)-(44).

\subsection{Quantitative Analysis}

Here we conduct a quantitative analysis of our production model to investigate whether the asset holdings that our model predicts match the ones observed in the data. We solve the model using approximation methods around a nonstochastic symmetric steady state. The approximated equations are provided in the appendix. Since markets are incomplete, we compute steady state asset holdings using the same methodology detailed in the appendix for section 2.3.2.

\subsubsection{Calibration}

Next, we describe in detail how we calibrate the various parameters in our model.

Preference parameters: We set $\beta$, the discount rate, as 0.99 , so that the quarterly real interest rate is $4 \%$, and using the estimated value of $\sigma$, the risk aversion parameter, in Smets and Wouters (2008), set it to 1.5. We choose $v$, the inverse of the Frisch elasticity of labor supply, to be 4 . In accordance with many papers in international macroeconomics, such as Chari et al (2002), we pick $a$, the parameter governing home bias in consumption, as 0.76 . There is no empirical consensus in the literature on the value of $\eta$, the elasticity of substitution between domestic and foreign goods, so we consider a range of values from $0.95-4$. This range encompasses values used in the literature such as Coeurdacier et al (2007) and Chari et al (2002). We set $\theta$ as 11, which implies a before-tax profit share in the economy of $9 \%$. This value is in the ballpark of the literature. ${ }^{28}$

Policy parameters: For the parameters governing monetary and tax policy rules, $\gamma$ and $\phi$, respectively, to ensure the existence and uniqueness of the price level, a sufficient condition is $\gamma, \phi>1$ (in which case monetary policy

\footnotetext{
${ }^{28}$ Rotemberg and Woodford (1997) estimate profit share to be $15 \%$ while Giannoni and Woodford (2003) estimate it to be $4 \%$.
} 
will be "active" and fiscal policy "passive"). ${ }^{29}$ We pick $\gamma, \phi=1.5$ in the baseline calibration. ${ }^{30}$ Our results are robust to the particular values that we pick for these parameters, as long as an unique equilibrium exists. We set $y$ to be 4 , which implies that $80 \%$ of total tax revenue is through labor taxes and $20 \%$ through profit taxes. We choose $\bar{B}$ as 1.26 , which implies a steady state debt-to-GDP ratio of $126 \%$. Our results are also robust to the exact number that we pick for these parameters and we view these calibrations as a plausible benchmark for advanced economies. The parameter $x$, which governs the portion of government spending that falls on domestic goods vs. foreign goods, is important for our analysis. We could use Corsetti and Muller (2006) to calibrate this parameter. Their estimate would suggest a value of $x$ around 9 for advanced economies. Here, we take a more conservative approach and use a wide range of values of $x$, from 1.5 to 9 , to check the robustness of our results. We then discuss the range of values for $x$ that is needed to generate home bias in equities that is observed in the data.

Exogenous processes: To estimate these parameters, we use quarterly US data from 1972:1 - 2008:4 and impose symmetry for the two countries. Using the production function, we can measure the aggregate productivity shocks exactly as $\log \left(A_{t}^{i}\right)=\log \left(Y_{t}^{i}\right)-\log \left(L_{t}^{i}\right), i=H, F$. Using real GDP and total non-farm hours, we estimate $\rho_{A}=0.98$ and $\sigma_{A}^{2}=0.0036 \%$. Since we set $\gamma=1.5$, we then use eqn.(40) to measure nominal shocks. Using the Fed funds rate and CPI inflation, we estimate $\rho_{R}=0.45$ and $\sigma_{R}^{2}=0.0083 \%$. Finally, for government expenditure shocks, we use real Federal consumption expenditure and estimate $\rho_{G}=0.966$ and $\sigma_{G}^{2}=0.0077 \%$. We assume that these exogenous processes are uncorrelated across the two countries. These parameters are important for our analysis since they define the risk that portfolio decisions respond to. For this reason, we conduct several robustness checks on the calibration of these parameters, as detailed in the robustness section below. None of the alternate calibrations change the quantitative conclusions of the paper.

\footnotetext{
${ }^{29} \mathrm{An}$ "active" monetary policy regime is one where interest rates respond strongly enough to inflation while a "passive" fiscal regime is one where tax revenues respond strongly enough to real debt. Also note that the bound on the fiscal policy rule to make it "passive" can depend on whether one allows a response of tax revenues to real debt or the maturity value of real debt.

${ }^{30}$ We do not attempt to calibrate these parameters because of the extremely simple policy rules that we use. We simply pick symmetric values for the feedback parameters on the policy rules.
} 


\subsubsection{Results}

Table 4 reports the steady state asset holdings of our model using the parameter values listed in table 3 . The results of our calibrated model, with consistently higher than $70 \%$ of asset holdings in domestic assets, match quantitatively the empirical findings for a wide range of parameter values for the elasticity of substitution and the relative proportion of government spending falling on domestic goods vs. foreign goods. ${ }^{31}$ Given the difficulty in the literature in generating empirically valid portfolio bias for reasonable parameter values, we view these results as a contribution of our paper. ${ }^{32}$

The intuition for home bond bias is the same as in section 2 . In the model, for bonds with nominal returns known one period in advance, the risk that agents face is in the form of realized real returns next period. When a positive interest rate shock hits, then the agents will realize lower real return on domestic bonds. ${ }^{33}$ With lower realized real returns however, the expected value of future taxes on domestic agents will be lower through the intertemporal government budget constraint. Therefore, real return on domestic bonds and taxes co-move positively in our model and since the government taxes only domestic agents, agents hold predominantly domestic bonds to achieve optimal risk-sharing. The reason why there is some holdings of foreign bonds is because now monetary shocks at home have spillovers on foreign price level and relative price levels under incomplete markets, like in section 2.3.2.

In this model, there are two reasons for home equity bias. First, a positive domestic government spending shock that falls relatively more on domestic goods will increase the relative price of the domestic good and imply an improvement in the terms of trade for the domestic economy. This means that the relative return of claims on the domestic good is higher compared to the claims on the foreign good. Since government spending has increased, in order to fulfill the intertemporal government budget constraint, domestic taxes have to increase. Therefore, in order to hedge against this risk, agents will want to hold an asset that offers a relatively higher return. With government spending

\footnotetext{
${ }^{31}$ Notice that the portfolio holdings are sometimes non-monotonic functions of the parameters. As we have shown with analytical solutions in our simple model, this is to be expected, especially under incomplete markets.

${ }^{32}$ While the focus of our paper is on the prediction of the model on portfolio holdings, the model produces reasonable values for some standard open economy moments. We provide these results in the appendix.

${ }^{33}$ In other words, expected inflation increases.
} 
falling relatively more on domestic goods, domestic equity is precisely such an asset. So, just the presence of government spending shocks that fall asymmetrically on domestic vs. foreign goods is sufficient to generate home bias in equity, just like in the model in section 2.3.

Second, in this production model, the presence of profit taxes create an additional hedging motive to hold domestic equity independently of the distribution of government spending on domestic vs. foreign goods. When a government spending shock hits, regardless of how it falls relatively on domestic goods vs. foreign goods, it leads to higher taxes, both on profits and labor. With part of those taxes falling on profits of domestic firms, this implies that returns on domestic equity will be lower. On the other hand, as is standard in this kind of models, higher government spending which leads to negative wealth effects due to higher taxes, leads to greater labor income as agents work more. While taxes on labor income increase as well, with our calibration, the negative wealth effect channel dominates and labor income net of taxes are higher. ${ }^{34}$ Thus, labor income and equity income will be negatively correlated if agents hold more of an asset with lower returns. Domestic equity is precisely such an asset. This is why here the value of $x$ at which there is significant bias in equity holdings is lower than $\frac{a}{1-a}$.

To clearly see the crucial role played by government expenditure shocks in our results for equity holdings, we report the asset holdings for the model with the same calibration for the other shocks, but after shutting down government expenditure shocks. The home equity bias result disappears, unless $\eta<1$, as shown in table 5.

\subsubsection{Alternative Calibrations}

The results above are robust to various alternative calibrations of the parameters governing the shocks. First, we experiment with the estimated values for the shocks in Justiniano et al (2008). Second, we allow for decreasing returns on labour, which affects the estimation of the productivity shocks, and also some of the model equations. Third, we also allow for $\gamma=2,2.5$, and 3, which affects the estimation of the nominal shocks. Fourth, we re-calibrate the shocks in different time periods (i) 1954:1 - 2008:4, (ii)1979:1 - 2008:4, and

\footnotetext{
${ }^{34}$ Numerically, we find that this holds unless $\theta$, which determines steady-state profits, is very low.
} 
(iii) 1972:1 - 2000:4. None of these alternative calibrations change significantly the quantitative conclusions of the paper. ${ }^{35}$

\subsection{Model Extensions}

We now extend the model by introducing two features: (i) longer average maturity of government debt and (ii) capital as an input in production. We do this to address two potential concerns on the model of section 3.1. By assuming only one-period bonds, we could be over-emphasizing the role of price level in the returns on government debt since all surprise in returns would come form unforeseen movements in the price level. Moreover, by assuming no capital, we would be disregarding the role of revaluation of capital wealth on portfolio choice. Our results below show that these extensions do not affect our quantitative conclusions on home asset bias. We provide the new elements of the model below while presenting the full derivations in the appendix.

\subsubsection{Setup}

First, rather than considering only one-period debt, we follow Woodford (2001) and allow for the existence of a general portfolio of government debt $B_{t}^{H, m}$ that has price $Z_{t}^{H, m} \cdot{ }^{36}$ Households engage on trade of this general government debt instrument. In particular, this instrument's payment structure is $\rho^{T-(t+1)}$ for $T>$ $t$ and $0 \leq \rho \leq 1$. Thus, the value of this portfolio of bond issued in period $t$ in $t+j$ is given by $Z_{t+j}^{H, m-j}=\rho^{j} Z_{t+j}^{H, m}$. We interpret this general instrument as a portfolio of infinitely many bonds, whose weights are given by $\rho^{T-(t+1)}$. Thus, $\rho$ determines the average maturity of government debt: when $\rho=0$, all debt is of one-period maturity. ${ }^{37}$

Second, we allow for capital as an input in production. We however, do not allow for capital accumulation because in an important contribution, Heathcote and Perri (2008) show that home equity bias can emerge in a two-country two-good model with investment and technology shocks. Our mechanism is independent and complementary to theirs and therefore, in order to highlight the quantitative significance of our proposed explanation in isolation, we do

\footnotetext{
${ }^{35}$ All the details on the calibrated parameters and the asset holding results are available on request from the authors.

${ }^{36}$ Here we use the index $m$ to denote the fact that this bond has a certain duration in period $t$.

${ }^{37}$ The average maturity of the portfolio is given by $(1-\beta \rho)^{-1}$.
} 
not present a model with investment. In this set-up, the constant returns to scale production function now takes the form

$$
y_{t}^{H}(j)=A_{t}^{H}\left(l_{t}^{H}(j)\right)^{\alpha}\left(k_{t}^{H}(j)\right)^{1-\alpha}
$$

where $k_{t}^{H}(j)$ is capital used in production by firm $j$ and $\alpha$ is the share of labor. A new condition now governs the optimal choice of inputs by firms and is given by

$$
\frac{w_{t}^{H} l_{t}^{H}(j)}{r_{t}^{H} k_{t}^{H}(j)}=\frac{\alpha}{1-\alpha}
$$

where $r_{t}^{H}$ is the rental rate of capital. The optimal pricing decision is given by

$$
p_{t}^{H h}(j)=\frac{\theta}{\theta-1} \frac{P_{t}^{H}}{A_{t}^{H}}\left(\frac{\left(w_{t}^{H}\right)^{\alpha}\left(r_{t}^{H}\right)^{1-\alpha}}{(1-\alpha)^{1-\alpha} \alpha^{\alpha}}\right)
$$

Moreover, the supply of capital is fixed in the aggregate $\int_{0}^{1} k_{t}^{H}(j) d j=K^{H}$.

Finally, to keep the structure of the model close to the baseline case, we do not allow for trade in claims to capital and therefore, equity holdings are still defined as claims to aggregate after-tax profits of firms. The domestic agent thus simply owns the capital stock $K^{H}$ and rents it out to domestic firms at the rate $r_{t}^{H}$ in a competitive market. The consumer budget constraint is then given by

$$
\begin{aligned}
& C_{t}^{H}+Z_{t}^{H, m} \frac{B_{t}^{H h, m}}{P_{t}^{H}}+Z_{t}^{F, m} \frac{B_{t}^{H f, m}}{P_{t}^{F}} Q_{t}+q_{t}^{H} E_{t}^{H h}+q_{t}^{F} E_{t}^{H f} Q_{t}=\left(1-\tau_{t}^{L}\right) w_{t}^{H} L_{t}^{H}+r_{t}^{H} K^{H}+ \\
& \frac{\left(1+\rho Z_{t}^{H, m}\right) B_{t-1}^{H h, m}}{P_{t}^{H}}+\frac{\left(1+\rho Z_{t}^{F, m}\right) B_{t-1}^{H f, m} Q_{t}}{P_{t}^{F}}+\left(q_{t}^{H}+\Pi_{t}^{H}\right) E_{t-1}^{H h}+\left(q_{t}^{F}+\Pi_{t}^{F}\right) Q_{t} E_{t-1}^{H f} .
\end{aligned}
$$

and the home consumer's Euler equations from choices over bond holdings now take the form

$$
\frac{1}{\left(C_{t}^{H}\right)^{\sigma}}=E_{t}\left[\frac{\beta P_{t}^{H}\left(1+\rho Z_{t+1}^{H, m}\right)}{\left(C_{t+1}^{H}\right)^{\sigma} P_{t+1}^{H} Z_{t}^{H, m}}\right]=E_{t}\left[\frac{\beta P_{t}^{F}\left(1+\rho Z_{t+1}^{F, m}\right) Q_{t+1}}{\left(C_{t+1}^{H}\right)^{\sigma} P_{t+1}^{F} Z_{t}^{F, m} Q_{t}}\right]
$$


The period home government budget constraint in this set-up is then given by

$$
\begin{aligned}
Z_{t}^{H, m} \frac{B_{t}^{H, m}}{P_{t}^{H}}= & \frac{B_{t-1}^{H, m}}{P_{t}^{H}}\left(1+\rho Z_{t}^{H, m}\right)+G_{t}^{H h} \frac{P_{t}^{H h}}{P_{t}^{H}}+G_{t}^{H f} \frac{P_{t}^{H f}}{P_{t}^{H}} \\
& -\tau_{t}^{\pi}\left(P_{t}^{H h}-\frac{\left(w_{t}^{H}\right)^{\alpha}\left(r_{t}^{H}\right)^{1-\alpha}}{(1-\alpha)^{1-\alpha} \alpha^{\alpha} A_{t}^{H}} P_{t}^{H}\right) \frac{Y_{t}^{H}}{P_{t}^{H}}-\tau_{t}^{L} w_{t}^{H} L_{t}^{H}
\end{aligned}
$$

\subsubsection{Results}

We need to calibrate some additional parameters in this extended model. We calibrate the steady-state capital to output ratio to be 10 (consistent with a quarterly model). Next, we try values of $\alpha$ ranging from $\frac{2}{3}$ and 1 and of $\rho$ from 0 to 1 . For the rest of the parameters, we use the values in table 3.

Fig. 2 shows that our results on home asset bias are robust to this model extension for a wide range of values for $\alpha$ and $\rho .{ }^{38}$ For all the parameter values, domestic bond positions are always above $53 \%$ and below $147 \%$ while domestic equity positions are between $78 \%$ and $92 \%$. Finally, note that when $\rho=0$ and $\alpha=1$, the portfolio positions replicate our results in section 3.2. Our preferred calibration is one where $\alpha=0.7$ and $\rho$ is set such that the median maturity of government debt is equal to 3 years, as it was in February 2012. In this case, the model display strong bias towards both domestic bonds (146\%) and domestic equity (89\%). Moreover, in the appendix, we show that when we shut down the government expenditure shock for this set of parameter values, the home bias for equity disappears and in fact, optimal portfolio allocation implies a strong position in foreign equity.

\section{Empirical Evidence}

In this section, we discuss in detail existing empirical evidence and our own empirical exercises, beyond the quantitative exercise above, that additionally validate the key mechanisms of our paper.

\subsection{Home Bond Bias}

We first discuss the empirical evidence in support of the mechanism that leads to home bond bias in our paper. Note that in our model the government

\footnotetext{
${ }^{38}$ For this set of results we used $x=4$ and $\eta=2$. Our results are robust to these values.
} 
satisfies an intertemporal budget constraint. In an important paper, Bohn (1998) shows evidence consistent with this for the U.S. by estimating a positive response of primary surplus to changes in debt. Still, the evidence that is directly relevant for our result is a positive correlation between real returns on government bonds and the net present value of expected future primary surpluses. ${ }^{39}$ To investigate this in the data, we follow the seminal approach of Gourinchas and Rey (2007). Following their strategy, we decompose the evolution of the government debt to primary surpluses and debt returns. Then, we verify if the present value of discounted primary surplus comoves with realized returns on government debt, and in particular, with inflation.

Generally, the law of motion of the government debt is given by

$$
b_{t}=b_{t-1}\left(1+r_{t-1}-\pi_{t}-g_{t}\right)+d_{t}
$$

where $b_{t}$ is government debt over GDP, $r_{t-1}$ is the average interest rate paid, $\pi_{t}$ is inflation, $g_{t}$ is GDP growth rate, and $d_{t}$ is primary deficit over GDP. We allow for trends in debt and deficits and approximate the budget constraint as

$$
\hat{b}_{t}=\frac{1}{\bar{\rho}}\left(\hat{b}_{t-1}+\tilde{r}_{t}\right)+\hat{d}_{t}
$$

following the standard practice of approximating variables and assuming that the budget constraint holds along the trend. ${ }^{40}$ In particular, note that $\tilde{r}_{t}=\hat{r}_{t-1}-$ $\hat{\pi}_{t}-\hat{g}_{t}$. Iterating on eqn.(45) forward and taking expectations, we have

$$
\hat{b}_{t-1}=-E_{t-1} \sum_{s=0}^{\infty}(\bar{\rho})^{s} \tilde{r}_{t+s}-\bar{\rho} E_{t-1} \sum_{s=0}^{\infty}(\bar{\rho})^{s} \hat{d}_{t+s} .
$$

After calibrating $\bar{\rho}$, we can use data on $\tilde{b}_{t-1}, \hat{r}_{t}, \hat{\pi}_{t}, \hat{g}_{t}$, and $\hat{d}_{t}$, together with eqn.(46) to decompose the evolution of the government debt to primary surpluses and debt returns using a VAR methodology. ${ }^{41}$ We describe the

\footnotetext{
${ }^{39}$ Notice that in the simple two period model in section 2 , one needs a contemporaneous correlation between primary surplus and real returns on debt. In a more general intertemporal model, such as the one in section 3, what is essential for our results is not the contemporaneous correlation, but rather a positve correlation between realized real bond returns and the net present value of expected future primary surpluses.

${ }^{40}$ Here, let $x^{S S}$ be the steady state value of variable $x, d$ the trend growth of debt such that $\frac{b_{t}^{s s}}{b_{t-1}^{s s}}=d$, and $\rho=1+r^{s s}-\pi^{s s}-g^{s s}$. Also let $\frac{r_{t-1}-r^{s s}}{1+r^{s s}-\pi^{s s}-g^{s s}}=\hat{r}_{t-1}, \frac{\pi_{t}-\pi^{s s}}{1+r^{s s}-\pi^{s s}-g^{s s}}=$ $\hat{\pi}_{t}, \frac{g_{t}-g^{s s}}{1+r^{s s}-\pi^{s s}-g^{s s}}=\hat{g}_{t}, \widehat{d}_{t}=\frac{d_{t}-d f_{t}^{s s}}{b_{t}^{s s}}$, and $\widehat{b}_{t}=\frac{b_{t}-b_{t}^{s s}}{b_{t}^{s s}}$. Finally, let $\tilde{r}_{t}=\hat{r}_{t-1}-\hat{\pi}_{t}-\hat{g}_{t}$ and $\bar{\rho}=\frac{\rho}{d}$.

${ }^{41}$ We calibrate $\bar{\rho}=0.99$, take out a linear trend from the relevant data, and use 1 lag
} 
details in the appendix. Note here that we need a VAR exercise to compute the expected future values of the variables on the right hand side of eqn.(46). In order to perform the exercise, we use the data constructed by Hall and Sargent (2011) on effective returns of holding U.S. government debt, that accounts for revaluation of debt in addition to interest paid. That is, the Hall and Sargent (2011) dataset contains the required information on $\tilde{r}_{t}=\hat{r}_{t-1}-\hat{\pi}_{t}-\hat{g}_{t}$ and by properly measuring revaluation effects, allows us to investigate the correlation between primary surpluses and realized effective returns.

After the decomposition, we then conduct direct tests of our mechanism. First, is there a positive correlation between $\tilde{r}_{t}$ and $-\bar{\rho} E_{t-1} \sum_{s=0}^{\infty}(\bar{\rho})^{s} \hat{d}_{t+s}$ in the data? We find the correlation to be $40.4 \%$. Second, we investigate whether there is direct evidence for a positive correlation between $\hat{\pi}_{t}$ and $\bar{\rho} E_{t-1} \sum_{s=0}^{\infty}(\bar{\rho})^{s} \hat{d}_{t+s}$, which is in fact the central mechanism behind our paper. Indeed, we find that the correlation is $26.2 \% .^{42}$

It is also worth noting that since our model posits that government debt provides a hedge against nominal risk, a prediction is that the formation of a monetary union should lower home debt bias. The evidence from the European Union is in support of this prediction: Schoenmaker and Bosch (2008) and De Santis and Gerard (2009) show that the introduction of the Euro has decreased the bond bias in Europe and that this decline is strongest for EMU countries. We also want to emphasize that our paper focuses only on explaining the evidence on the overwhelming share of domestic nominal bonds on total nominal bond holdings of private agents. Thus, it is silent on other interesting topics on global imbalances and reserve accumulation or its composition. In particular, the recent accumulation of international reserves by central banks of developing countries that led to a considerable fraction of US government bonds being held by foreigners is not the focus nor is it directly relevant for the mechanism studied in this paper. ${ }^{43}$ The central piece of evidence that is

in the VAR. Our results are robust to alternate calibration of $\bar{\rho}$, de-trending the data at a different frequency, and using 2 instead of 1 lag.

${ }^{42}$ Note here that since $\tilde{r}_{t}=\hat{r}_{t-1}-\hat{\pi}_{t}-\hat{g}_{t}$, our results show that the correlation between $\tilde{r}_{t}$ and $\bar{\rho} E_{t-1} \sum_{s=0}^{\infty}(\bar{\rho})^{s} \hat{d}_{t+s}$ is being driven by the correlation between $\hat{\pi}_{t}$ and $\bar{\rho} E_{t-1} \sum_{s=0}^{\infty}(\bar{\rho})^{s} \hat{d}_{t+s}$, and not $\hat{r}_{t-1}$ and $\bar{\rho} E_{t-1} \sum_{s=0}^{\infty}(\bar{\rho})^{s} \hat{d}_{t+s}$.

${ }^{43}$ For example, one might wonder if our model mechanisms can be consistent with the 
explained by the mechanism proposed in this paper is that private agents are biased towards holding primarily domestic nominal government bonds. ${ }^{44}$

So far, we have not discussed default risk and how that might potentially affect our results. It is clear that simply allowing for default risk has exactly the same implications for bond portfolio choice as our current set-up. If a country's government defaults on its debt, then while the return on debt goes down, so does the tax burden on its citizens due to the intertemporal budget constraint. Thus, again, holding primarily domestic bonds constitutes an optimal portfolio decision. How about if the government can practice discriminatory default, thereby punishing foreign creditors in an asymmetric fashion? While this is a theoretical possibility, the empirical evidence for this case, as argued by Broner and Ventura (2011) and Gennaioli, Martin, and Rossi (2011), is rather weak, especially in recent times.

\subsection{Home Equity Bias}

Now, we discuss the empirical evidence in support of our mechanism for equity bias. The most direct and relevant test of our model mechanism however is whether there is a positive correlation between government spending shocks and equity returns. Belo at al (2010) provide evidence that sectors that are more exposed to government spending have higher equity returns under Democratic presidential tenure. ${ }^{45}$ They thus provide an explanation for the presidential pricing puzzle documented by Santa-Clara and Valkanov (2003) who

large negative foreign asset position of the United States with the rest of the world and the fact that U.S. private investors hold around $40 \%$ of the stock of U.S. government debt. It is true that our model currently cannot match such an empirical finding since we focus on symmetric countries to highlight our mechanism and thus, do not model one country dissaving substantially. At the same time however, we want to emphasize that in a model of asymmetric countries, both a negative foreign asset position and home bond bias in the precise sense we define in the paper can be reconciled with our mechanism at work.

${ }^{44}$ Like all papers that assume PPP, we are also subject to the critique that in the data, nominal exchange rate is much more volatile than relative inflation rates. We cannot resolve the PPP puzzle in this paper. We do want to note however that in estimated DSGE models, the shock that drives most of the variation in nominal exchange rates is a random shock to the PPP equation. This shock at the same time is not very relevant for other macroeconomic variables. See for example, Lubik and Schorfheide (2005). In such a case, if agents use forward contracts on nominal exchange rates to hedge against movements induced by this shock, then nominal bonds will continue to have a role to hedge against price level movements. The mechanism of our paper would then still be relevant in generating bias in nominal government bonds.

${ }^{45}$ They use the Benchmark Input-Output Accounts released by the BEA to construct a measure of industry's exposure to government spending. 
had shown that excess returns in the stock market is higher under Democratic compared to Republican presidencies. Belo et al (2010) show that the key mechanism for their results is due to the positive effect of government spending on future profitability of firms. Moreover, as independent validation, Belo et al (2010) also show that the difference in stock price performance of firms with different government exposure is positively correlated with the measure of government spending shocks identified by Ramey (2009).

As an additional test, we also use the identification mechanism of Blanchard and Perotti (2002) in quarterly U.S. data from to 1947-2009 to construct a series of government expenditure shocks. ${ }^{46}$ We correlate this series of shocks with the series of S\&P 500 quarterly returns. These correlations are between $5 \%$ and $10 \%$, depending on the number of lags used in the the VAR and on the assumptions on the elasticity of total tax to output. We thus conclude that there indeed is evidence for our mechanism of generating home equity bias in the U.S. data.

In addition, a general result of our paper is that to generate equity home bias, a sufficient condition is for the government's consumption to be roughly more biased than the consumer's towards domestic goods. What is the empirical support for this requirement? Corsetti and Muller (2006) provide the most direct evidence where they show that for many OECD countries, government spending has the lowest import content when compared to private consumption and investment. For example, for the U.S. they find that the import content is $5.8 \%$ in government spending, $11.6 \%$ in private consumption, and $15.8 \%$ in investment. Moreover, in our model, government spending shocks improve the terms of trade. There is empirical support for this model feature: for example, Monacelli and Perotti (2008), Muller (2008), and Corsetti and Muller (2006) find that for the U.S., the terms of trade appreciates in response to a government spending shock. ${ }^{47}$

\footnotetext{
${ }^{46}$ In the VAR specification, the data series comprises federal government consumption, a tax aggregate as defined in Blanchard and Perotti (2002), and GDP.

${ }^{47}$ There is some evidence, such as in Monacelli and Perrotti (2006), that a government spending shock depreciates the real exchange rate. They do not directly identify the effect on the terms of trade, however. With preference bias in consumption, our model would predict the real exchange rate appreciating in response to a government spending shock. Even then, Beetsma et al. (2008), Froot and Rogoff (1991), and Frankel and Razin (1992) find that government spending appreciates the real exchange rate.
} 


\section{Conclusion}

In this paper, in a standard frictionless international macroeconomic model with trade in equity and a government that issues nominal bonds, we showed that equilibrium portfolios are biased towards domestic equity and debt. In the model, holding domestic nominal debt offers insurance against shocks to bond returns and the resulting movement in taxes, while holding domestic equity offers optimal hedging against government expenditure shocks that fall relatively more on domestic goods.

For there to be domestic bias in nominal bonds, only two features of the model are essential. First, there has to be some uncertainty in the government bond returns. Second, the government has to tax relatively more domestic agents than foreign agents. The result is robust to a wide range of preference parameter values and a variety of extensions such as incomplete markets, infinite horizon, production economy, and distortionary taxation. We also showed that in a variety of settings, complete or incomplete markets, log utility or general CRRA utility, home consumption bias or not, a sufficient condition for home bias in equity is that government spending is more biased towards domestic goods as compared to the consumer. Importantly, we generate home equity bias without depending on the value of $\eta$, the elasticity of substitution between domestic and foreign goods.

Empirically, we provided two sources of evidence for our model mechanisms. First, we showed that a calibrated dynamic production economy version of the model generates asset holdings that quantitatively matches empirical findings. Second, outside of our quantitative model, using a wide range of tools and the findings of the existing literature, we also showed evidence in the data consistent with the key mechanisms that drive our results. 


\section{References}

[1] Backus, D. K., P. J. Kehoe and F. E. Kydland, 1994, "Dynamics of the Trade Balance and the Terms of Trade: The J-Curve?," American Economic Review, 84, 84-103.

[2] Barro, R. J., 1974, "Are Government Bonds Net Wealth?," Journal of Political Economy, 82, 1095-1117.

[3] Baxter, M. and U. J. Jermann, 1997, "The International Diversification Puzzle is Worse Than You Think," American Economic Review, 87, 17080.

[4] Beetsma, R., M. Giuliodori, and F. Klaasen, 2008, "The Effects of Public Spending Shocks on Trade Balances and Budget Deficits in the European Union," Journal of the European Economic Association, 6, 414-423.

[5] Belo, F., V. Gala, and J. Li, 2010, "Government Spending, Political Cycles, and the Cross-section of Stock Returns," Working paper, University of Minnesota.

[6] Benigno, P. and S. Nistico, 2012, "International Portfolio Allocation under Model Uncertainty," American Economic Journal: Macroeconomics, 4, 144-89.

[7] Blanchard O. and R. Perotti, 2002, "An Empirical Characterization of the Dynamic Effects of Changes in Government Spending and Taxes on Output," Quarterly Journal of Economics, 117, 1329-1368.

[8] Bohn, H., 1998, "The Behavior of U.S. Public Debt and Deficits," Quarterly Journal of Economics, 113, 949-963.

[9] Broner, F. and J. Ventura, 2011, "Globalization and Risk-Sharing," Review of Economic Studies, 78, 49-82.

[10] Burger, J. D. and F. E. Warnock, 2003, "Diversification, Original Sin, and International Bond Portfolios," working paper.

[11] Chan, K., V. M. Covrig, and L. K. Ng, 2005, "What Determines the Domestic and Foreign Bias? Evidence from Mutual Fund Equity Allocations Worldwide," Journal of Finance, 60, 1495-1534. 
[12] Chari, V. V., P. J. Kehoe, and E. McGrattan, 2002, "Can Sticky Price Models Generate Volatile and Persistent Real Exchange Rates?," Review of Economic Studies, 69, 533-63.

[13] Cole, H. L. and M. Obstfeld, 1991, "Commodity Trade and International Risk Sharing: How much do Financial Markets Matter?," Journal of Monetary Economics, 28, 3-24.

[14] Corsetti, G., L. Dedola, and S. Leduc, 2008, "International Risk Sharing and the Transmission of Productivity Shocks," Review of Economic Studies, 75, 443-473.

[15] Corsetti, G. and P. Pesenti, 2001, "Welfare and Macroeconomic Interdependence," Quarterly Journal of Economics, 116, 421-445.

[16] Corsetti, G. and G. J. Muller, 2006, "Twin deficits: Squaring Theory, Evidence and Common Sense," Economic Policy, 21, 597-638.

[17] Coeurdacier, N., 2005, "Do Trade Costs in Goods Markets Lead to Home Bias in Equities?," working paper.

[18] Coeurdacier, N. and P. O. Gourinchas, 2008, "When Bonds Matter: Home Bias in Goods and Assets," working paper.

[19] Coeurdacier, N., R. Kollmann, and P. Martin, 2008, "International Portfolios, Capital Accumulation and Foreign Assets Dynamics," working paper.

[20] Coeurdacier, N., R. Kollmann, and P. Martin, 2007, "International Portfolios with Supply, Demand, and Redistributive Shocks," in NBER International Seminar in Macroeconomics, Chicago: University of Chicago Press.

[21] Coeurdacier, N. and H. Rey, 2011, "Home Bias in Open Economy Financial Macroeconomics," working paper.

[22] De Santis, R. and B. Gérard, 2009, "International Portfolio Reallocation: Diversification Benefits and European Monetary Union," European Economic Review, forthcoming.

[23] Devereux, M. and A. Sutherland, 2006, "Solving for Country Portfolios in Open Economy Macro Models," working paper. 
[24] Engel, C. and A. Matsumoto, 2009, "The International Diversification Puzzle when Goods Prices are Sticky: It's Really About Exchange Rate Hedging, not Equity Portfolios," American Economic Journal: Macroeconomics, 1, 155-188.

[25] Fidora, M., M. Fratzscher, and C. Thimann, 2007, "Home Bias in Global Bond and Equity Markets-the Role of Real Exchange Rate Volatility," Journal of International Money and Finance, 26, 631-55.

[26] Frankel, J. and A. Razin, 1992, Fiscal Policies and the World Economy, Cambridge: MIT Press.

[27] Froot, K. and K. Rogoff, 1991, "The EMS, The EMU, and The Transition to a Common Currency," in NBER Macroeconomics Annual, 6, Cambridge: MIT Press.

[28] Gennaioli, N., A. Martin, and S. Ross, 2011,"Sovereign Default, Domestic Banks and Financial Institutions," working paper.

[29] Giannoni, M. and M. Woodford, 2003, "Optimal Inflation Targeting Rules", in Inflation Targeting, Chicago: University of Chicago Press

[30] Gourinchas, P. O. and H. Rey, 2007, "International Financial Adjustment," Journal of Political Economy, 115, 665-703.

[31] Hall, G. and T. Sargent, 2011, "Interest Rate Risk and Other Determinants of Post WW-II U.S. Government Debt/GDP Dynamics," American Economic Journal: Macroeconomics, 3, 1-27.

[32] Heathcote, J. and F. Perri, 2008, "The International Diversification Puzzle Is Not as Bad as You Think," working paper.

[33] Julliard, C., 2006, "The International Diversification Puzzle Is Not Worse Than You Think," working paper.

[34] Justiniano, A, G. Primiceri, and A. Tambalotti, 2008, "Investment Shocks and Business Cycles," working paper.

[35] Kollmann, R., 2006, "International Portfolio Equilibrium and the Current Account," working paper. 
[36] Kyrychenko, V., 2005, "Home Bias in U.S. Household Portfolios," working paper.

[37] Lubik, T. and F. Schorfheide, 2005, "A Bayesian Look at New Open Economy Macroeconomics," in NBER Macroeconomics Annual, 20, Cambridge: MIT Press.

[38] Lucas, R. E. Jr., 1982, "Interest Rates and Currency Prices in a Twocountry World," Journal of Monetary Economics, 10, 335-359.

[39] Monacelli, T. and R. Perotti, 2008, "Openness and the Sectoral Effects of Fiscal Policy," Journal of the European Economic Association, 6, 395403.

[40] Monacelli, T. and R. Perotti, 2006, "Fiscal Policy, the Trade Balance and the Real Exchange Rate: Implications for International Risk Sharing," working paper.

[41] Muller, G. J., 2008, "Understanding the Dynamic Effects of Government Spending on Foreign Trade," Journal of International Money and Finance, 27, 345-371.

[42] Nechio, F., 2009, "Foreign Holdings: Is it the Same Decision as Having or not Stocks?," working paper.

[43] Rotemberg, J. and M. Woodford, 1997, "An Optimization-Based Econometric Framework for the Evaluation of Monetary Policy," in NBER Macroeconomics Annual, 12, Cambridge: MIT Press.

[44] Obstfeld, M., 2006, "International Risk Sharing and the Costs of Trade," Ohlin Lecture.

[45] Obstfeld, M., 1989, "Fiscal Deficits and Relative Prices in a Growing World Economy," Journal of Monetary Economics, 23, 461-84.

[46] Ramey, V. A., 2009, "Identifying Government Spending Shocks: It's all in the Timing," working paper.

[47] Santa-Clara, P. and R. Valkanov, 2003, "The Presidential Puzzle: Political Cycles and the Stock Market," Journal of Finance, 58, 1841-1872. 
[48] Schoenmaker. D. and T. Bosch, 2008, "Is the Home Bias in Equities and Bonds Declining in Europe?," Investment Management and Financial Innovations, 5, 90-102.

[49] Smets, F. and R. Wouters, 2008, "Shocks and Frictions in U.S. Business Cycles: A Bayesian DSGE Approach," working paper.

[50] van Wincoop, E. and F. E. Warnock, 2006, "Is Home Bias in Assets Related to Home Bias in Goods?," working paper.

[51] Woodford, M., 2001, "Fiscal Requirements for Price Stability," Journal of Money Credit and Banking, 33, 669-728. 


\section{Tables and Graphs}

\begin{tabular}{cccc}
\hline \hline & & & \\
Country & World mkt. share & Dom. stock share & $\begin{array}{c}\text { Home bias } \\
\text { AUS }\end{array}$ \\
AUS & 1.2 & 71.7 & 4.09 \\
CAN & 2.4 & 84 & 3.55 \\
FRA & 4.3 & 79.8 & 2.92 \\
GER & 4 & 61.3 & 2.72 \\
ITA & 2.2 & 67.3 & 3.42 \\
JPN & 11.3 & 89.5 & 2.06 \\
NLD & 2 & 43.6 & 3.03 \\
ESP & 1.4 & 86 & 4.11 \\
CHE & 2.2 & 45.6 & 3.03 \\
GBR & 8.1 & 77 & 2.25 \\
USA & 47.8 & 88.7 & 0.62 \\
\hline \hline
\end{tabular}

Table 1: Domestic equity bias. Source: Coeurdacier et al (2007). ${ }^{48}$

\footnotetext{
${ }^{48}$ World mkt share measures the share of domestic stocks in countries portfolios in 2001 for the biggest market capitalization (CPIS data). Dom. stock share measures the share of domestic stocks in a representative sample of mutual funds, averaged over the period 1999-2000 (Chan et al. (2005)).
} 


\begin{tabular}{|c|c|c|c|c|c|}
\hline \multicolumn{6}{|c|}{ Equity Holdings } \\
\hline & & $\eta=0.95$ & $\eta=1.2$ & $\eta=1.5$ & $\eta=2$ \\
\hline \multirow[t]{2}{*}{$a=0.5$} & no $G_{t}$ & $50 \%$ & $50 \%$ & $50 \%$ & $50 \%$ \\
\hline & $x=\frac{2 a}{1-a}$ & $192 \%$ & $223 \%$ & $230 \%$ & $200 \%$ \\
\hline \multirow[t]{2}{*}{$a=0.6$} & no $G_{t}$ & $104 \%$ & $31 \%$ & $43 \%$ & $46 \%$ \\
\hline & $x=\frac{2 a}{1-a}$ & $147 \%$ & $169 \%$ & $185 \%$ & $192 \%$ \\
\hline \multirow[t]{2}{*}{$a=0.7$} & no $G_{t}$ & $120 \%$ & $-8 \%$ & $32 \%$ & $42 \%$ \\
\hline & $x=\frac{2 a}{1-a}$ & $127 \%$ & $140 \%$ & $154 \%$ & $171 \%$ \\
\hline \multirow[t]{2}{*}{$a=0.8$} & no $G_{t}$ & $116 \%$ & $-1200 \%$ & $0 \%$ & $31 \%$ \\
\hline & $x=\frac{2 a}{1-a}$ & $114 \%$ & $122 \%$ & $131 \%$ & $144 \%$ \\
\hline
\end{tabular}

Table 2: Equity allocations without govt. exp. shocks vs. equity allocations with govt. exp. shocks and $x=\frac{2 a}{1-a}$, for different levels of consumption bias and elasticity of substitution. 


\begin{tabular}{cc|cc}
\hline \hline Parameters & Values & Parameters & Values \\
$\beta$ & 0.99 & $y$ & 4 \\
$\sigma$ & 1.5 & $\bar{B}$ & 1.26 \\
$\nu$ & 4 & $\rho_{A}$ & 0.98 \\
$a$ & 0.76 & $\rho_{g}$ & 0.966 \\
$\eta$ & $0.95-4$ & $\rho_{R}$ & 0.45 \\
$\theta$ & 11 & $\sigma_{a}^{2}$ & $0.0036 \%$ \\
$\gamma$ & 1.5 & $\sigma_{g}^{2}$ & $0.0077 \%$ \\
$\phi$ & 1.5 & $\sigma_{R}^{2}$ & $0.0083 \%$ \\
$x$ & $1.5-9$ & & \\
\hline \hline
\end{tabular}

Table 3: Parameter values used in the quantitative analysis of the model.

\begin{tabular}{|c|c|c|c|c|c|c|}
\hline \multicolumn{7}{|c|}{ Domestic Holdings } \\
\hline & & $x=1.5$ & $x=2$ & $x=4$ & $x=8$ & $x=9$ \\
\hline \multirow[t]{2}{*}{$\eta=0.95$} & Bonds & $88 \%$ & $93 \%$ & $98 \%$ & $104 \%$ & $105 \%$ \\
\hline & Equity & $80 \%$ & $83 \%$ & $86 \%$ & $91 \%$ & $91 \%$ \\
\hline \multirow[t]{2}{*}{$\eta=1.2$} & Bonds & $108 \%$ & $108 \%$ & $112 \%$ & $118 \%$ & $119 \%$ \\
\hline & Equity & $81 \%$ & $81 \%$ & $84 \%$ & $86 \%$ & $87 \%$ \\
\hline \multirow[t]{2}{*}{$\eta=1.5$} & Bonds & $110 \%$ & $110 \%$ & $113 \%$ & $115 \%$ & $115 \%$ \\
\hline & Equity & $79 \%$ & $79 \%$ & $81 \%$ & $83 \%$ & $83 \%$ \\
\hline \multirow[t]{2}{*}{$\eta=2$} & Bonds & $105 \%$ & $105 \%$ & $105 \%$ & $103 \%$ & $103 \%$ \\
\hline & Equity & $77 \%$ & $77 \%$ & $78 \%$ & $80 \%$ & $80 \%$ \\
\hline \multirow[t]{2}{*}{$\eta=4$} & Bonds & $84 \%$ & $81 \%$ & $78 \%$ & $78 \%$ & $75 \%$ \\
\hline & Equity & $74 \%$ & $74 \%$ & $74 \%$ & $74 \%$ & $75 \%$ \\
\hline
\end{tabular}

Table 4: Domestic asset holdings - quantitative model 
Domestic Holdings: No Government Expenditure Shocks

Equity

$\eta=0.95$

$118 \%$

$\eta=1.2$

$-100 \%$

$\eta=1.5$

$20 \%$

$\eta=2$

$40 \%$

$\eta=4$

$48 \%$

Table 5: Domestic asset holdings - no govt expenditure shocks

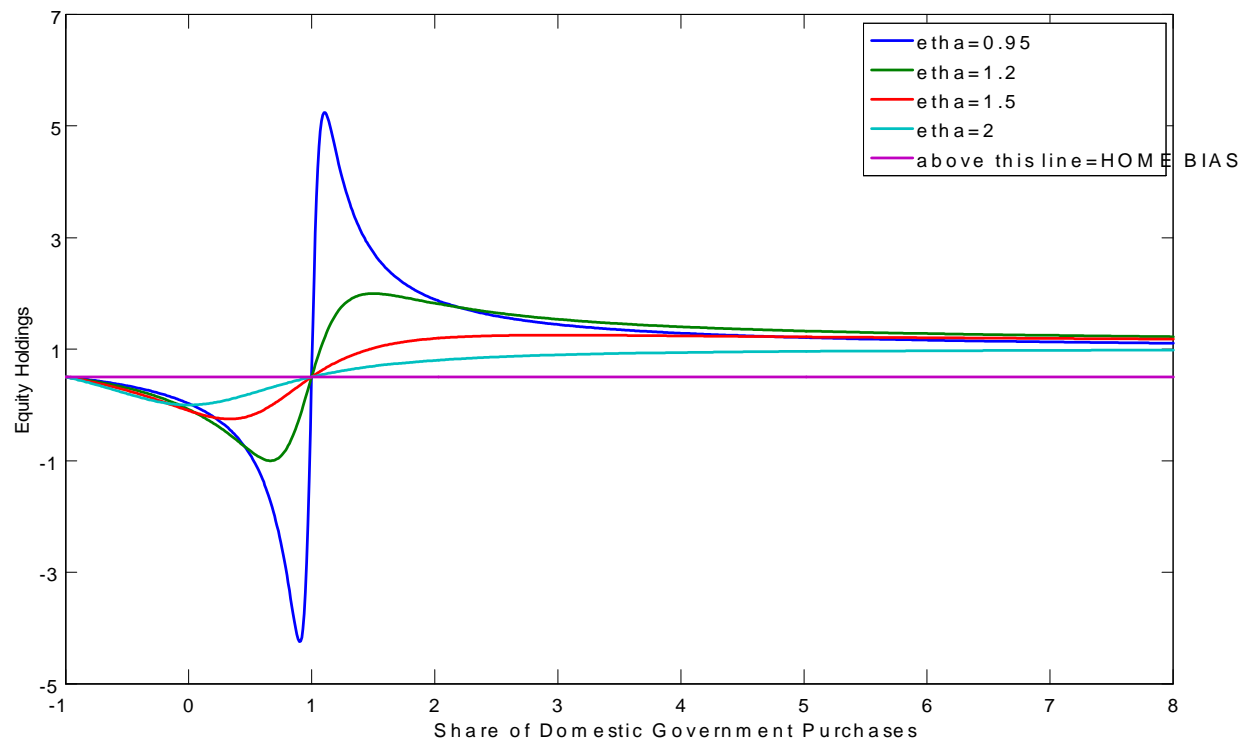

Fig 1: Equity holdings as a function of $x$ under general preferences and complete markets 

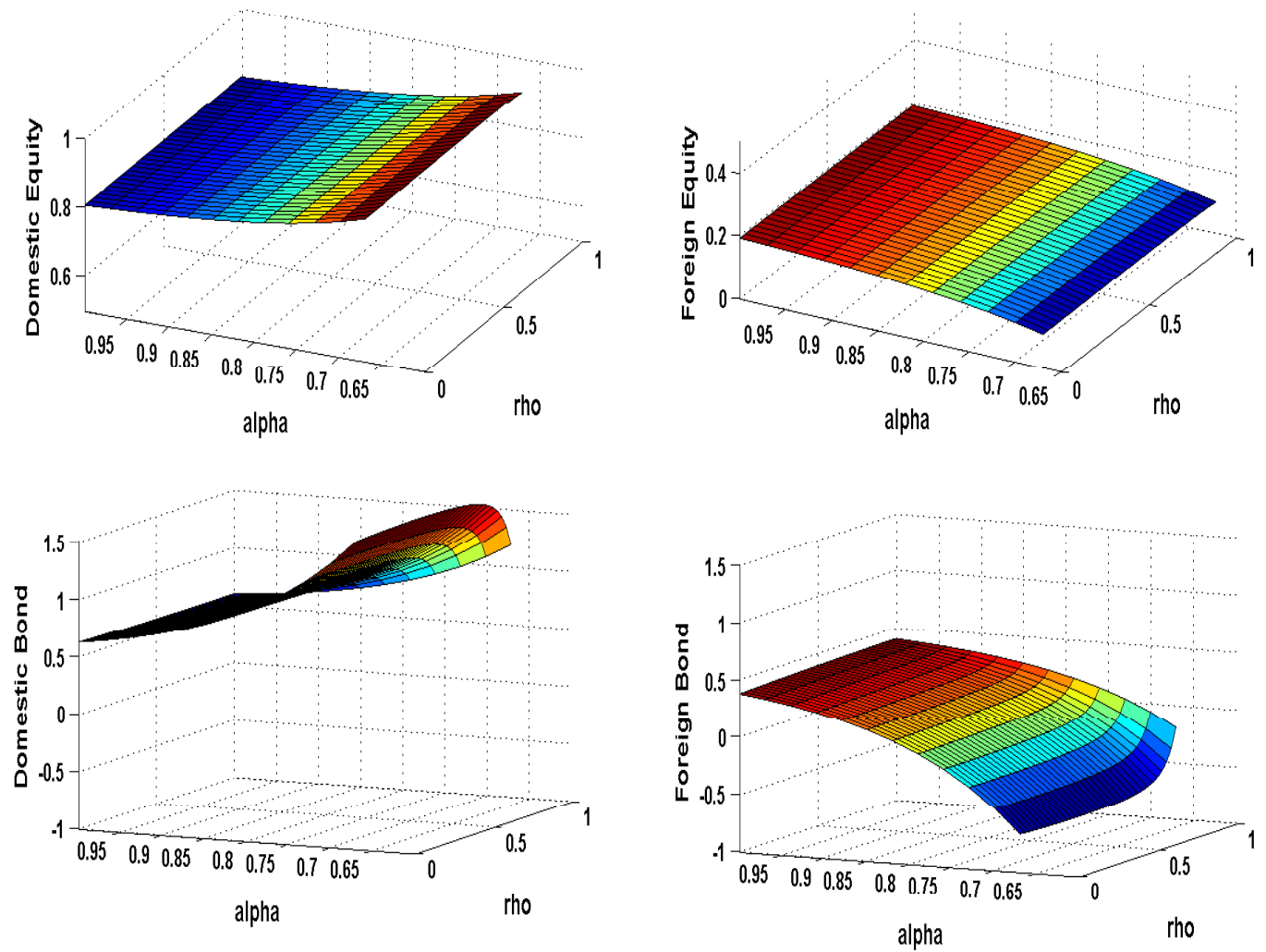

Fig 2: Asset holdings in the extended quantitative model 


\section{Appendix}

\subsection{Extensions of the two-period model}

Here we describe the log-linearized version of the model where all the shocks are present. We loglinearize around the symmetric non-stochastic values of the variables in period $1 .{ }^{1}$ We present the equations for the domestic agent only and the foreign agent's equations are analogous.

The domestic agent's optimality conditions for the two goods are:

$$
\hat{C}_{1}^{H f}-\hat{C}_{1}^{H h}=\eta\left(\hat{P}_{1}^{H h}-\hat{P}_{1}^{H f}\right) \quad \hat{C}_{1}^{F h}-\hat{C}_{1}^{F f}=\eta\left(\hat{P}_{1}^{F f}-\hat{P}_{1}^{F h}\right) .
$$

The definition of the consumption indices log-linearized gives

$$
\hat{C}_{1}^{H}=a \hat{C}_{1}^{H h}+(1-a) \hat{C}_{1}^{H f} \quad \hat{C}_{1}^{F}=a \hat{C}_{1}^{F f}+(1-a) \hat{C}_{1}^{F h}
$$

and the corresponding welfare based price indices are

$$
\hat{P}_{1}^{H}=a \hat{P}_{1}^{H h}+(1-a) \hat{P}_{1}^{H f} \quad \hat{P}_{1}^{F}=a \hat{P}_{1}^{F f}+(1-a) \hat{P}_{1}^{F h} .
$$

Next, the law of one price log-linearized gives

$$
\hat{P}_{1}^{H h}=\hat{S}_{1}+\hat{P}_{1}^{F h} \quad \hat{P}_{1}^{H f}=\hat{S}_{1}+\hat{P}_{1}^{F f} .
$$

Because we allow for consumption home bias and shocks lead to movements in relative prices, shocks will also affect the real exchange rate in our model. The real exchange rate follows

$$
\hat{Q}_{1}=(2 a-1)\left(\hat{P}_{1}^{H f}-\hat{P}_{1}^{H h}\right) .
$$

The goods market clearing relations are given by

$$
a \hat{C}_{1}^{H h}+(1-a) \hat{C}_{1}^{F h}+G_{1}^{H h}+G_{1}^{F h}=\hat{Y}_{1}^{H} \quad a \hat{C}_{1}^{F f}+(1-a) \hat{C}_{1}^{H f}+G_{1}^{H f}+G_{1}^{F f}=\hat{Y}_{1}^{F} .
$$

Finally, in the case where markets are complete, we have

$$
\sigma\left(\hat{C}_{1}^{H}-\hat{C}_{1}^{F}\right)=\hat{Q}_{1} .
$$

Let's derive the log-linear budget constraint. By the symmetry in the two countries and market clearing, we know that $E_{0}^{H h}=E_{0}^{F f}=\theta$ and $E_{0}^{H f}=E_{0}^{F h}=1-\theta$. We denote this holding by $\theta$ to simplify notation and to make clear that it does not depend on the realization of the shocks in $t=1$. Analogously, using the bond holdings' market clearing and assuming symmetry between the two governments' debt, i.e. $B_{0}^{H}=B_{0}^{F}$, we have that $B_{0}^{H h}=B_{0}^{F f}=z$ and $B_{0}^{H f}=B_{0}^{F h}=B-z$, where $z$ and $B=B_{0}^{H}=B_{0}^{F}$ are simplified notation. These relations simplify the consumer budget constraint as

$$
\hat{C}_{1}^{H}+\bar{\tau} \hat{\tau}_{1}^{H}=(\theta)\left(\hat{P}_{1}^{H h}-\hat{P}_{1}^{H}+\hat{Y}_{1}^{H}\right)-(\theta-1)\left(\hat{P}_{1}^{H f}-\hat{P}_{1}^{H}+\hat{Y}_{1}^{F}\right)-R_{0}^{H} z \hat{P}_{1}^{H}-R_{0}^{F}(B-z)\left(\hat{P}_{1}^{F}-\hat{Q}_{1}\right) .
$$

The government budget constraint is, up to a first order approximation

${ }^{1} \hat{\mathrm{k}}$ for $\log$ - deviations of $\mathrm{k}$ and $\overline{\mathrm{k}}$ for the value of the $\mathrm{k}$ in absence of shocks. 


$$
\bar{\tau} \hat{\tau}_{1}^{H}=G_{1}^{H h}+G_{1}^{H f}-R_{0}^{H} B \hat{P}_{1}^{H} .
$$

\subsubsection{Complete markets}

Proposition 2: Upto a first-order, (i) in the presence of nominal and government expenditure shocks, if (ii) the representative agent has CRRA utility, no preference bias in consumption, and CES preferences over domestic and foreign goods, (iii) the government taxes only domestic agents, and (iv) the government expenditure ratio between domestic goods and foreign goods is $x$, then (a) the agent holds only the bonds of her government (b) $x>1$ implies home equity bias.

Proof: Eqn.(8) becomes:

$$
\hat{C}_{1}^{H}+\bar{\tau} \hat{\tau}_{1}^{H}=(\theta)\left(\hat{P}_{1}^{H h}-\hat{P}_{1}^{H}+\hat{Y}_{1}^{H}\right)-(\theta-1)\left(\hat{P}_{1}^{H f}-\hat{P}_{1}^{H}+\hat{Y}_{1}^{F}\right)-R_{0}^{H} z \hat{P}_{1}^{H}-R_{0}^{F}(B-z)\left(\hat{P}_{1}^{F}-\hat{Q}_{1}\right) .
$$

Here, we derive the portfolio allocation with a general $a$ and $\sigma$ and in the end we relate to the specific case of the proposition where $a=0.5$. Using eqns.(9), (2), (6), and (7), we can write eqn.(10) as

$$
\begin{aligned}
G_{1}^{H h}+G_{1}^{H f}-G_{1}^{F h}-G_{1}^{F f} & =\left(2(2-\theta-a)+\frac{2 a-1}{\sigma}\right)\left(\hat{P}_{1}^{H h}-\hat{P}_{1}^{H f}\right) \\
& +R_{0}(B-z)\left(\hat{P}_{1}^{H}-\hat{P}_{1}^{F}\right)+R_{0}(B-z) \hat{Q}_{1} .
\end{aligned}
$$

Then, using eqns.(1), (2), (6), and (7), we get

$$
G_{1}^{H h}-G_{1}^{H f}+G_{1}^{F h}-G_{1}^{F f}=(2 a-1)\left(\frac{2 a-1}{\sigma}+\frac{(1-a) \eta}{a(2 a-1)}+\eta\left(\frac{1}{a}-2 a+1\right)\right)\left(\hat{P}_{1}^{H h}-\hat{P}_{1}^{H f}\right) .
$$

Eqns.(13) and (11) determine the stochastic process for $\hat{P}_{1}^{H h}-\hat{P}_{1}^{H f}$. Once we realize that $\left(\hat{P}_{1}^{H}-\hat{P}_{1}^{F}\right)$ is an exogenous stochastic process independent of all the government expenditure processes, the only way the two equations are consistent is when $z=B$. For the foreign agent, the proof is the same. This shows that each agent holds only her own government's bond.

From eqn.(13) and using $z=B$, we have

$$
G_{1}^{H h}-G_{1}^{F h}-G_{1}^{H f}-G_{1}^{F f}=\left[2(2+\theta-a)\left(\frac{2 a-1}{\sigma}\right)\right]\left(\hat{P}_{1}^{H h}-\hat{P}_{1}^{H f}\right) .
$$

Using that $G_{1}^{H h}=x G_{1}^{H f}$ and $G_{1}^{F f}=x G_{1}^{F h}$, we can re-write eqn.(13) as

$$
(x-1)\left(G_{1}^{H f}-G_{1}^{F h}\right)=(2 a-1)\left[\frac{2 a-1}{\sigma}+\frac{(1-a) \eta}{a(2 a-1)}+\eta\left(\frac{1}{a}-2 a+1\right)\right]\left(\hat{P}_{1}^{H h}-\hat{P}_{1}^{H f}\right)
$$

and eqn.(11) as

$$
(1+x)\left(G_{1}^{H f}-G_{1}^{F h}\right)=\left[2(2+\theta-a)+\left(\frac{2 a-1}{\sigma}\right)\right]\left(\hat{P}_{1}^{H h}-\hat{P}_{1}^{H f}\right) .
$$

Since eqns.(14) and (15) must hold for all realization of shocks and $\theta$ cannot be contingent on the 
shocks, we find that

$$
\theta=\frac{1}{2}+\frac{1}{2}(2 a-1)\left[\frac{1+x}{x-1}\left(\frac{2 a-1}{\sigma}-\frac{4 a \eta(a-1)}{2 a-1}\right)+1-\frac{1}{\sigma}\right] .
$$

With $a=0.5, \eta=1$ and $\sigma=1$, the equivalent of eqn.(16) is $\theta=\frac{1}{x-1}+1$. With $a=0.5$ and general $\eta$ and $\sigma$, eqn.(16) is $\theta=\frac{1}{2}\left(\frac{\eta(1+x)}{x-1}+1\right)$, and it follows trivially that $x>1$ implies $\theta>0.5$, that is, home bias in equity. This gives us the proof.

\subsubsection{Incomplete Markets}

Because markets are incomplete, we follow Devereux and Sutherland (2006) in order to compute equilibrium portfolios. This consists in satisfying a second order accurate approximation of the household Euler equation, which in our case has the form:

$$
E_{0}\left[\left(\hat{C}_{1}^{H}-\hat{C}_{1}^{F}-\frac{\hat{Q}_{1}}{\sigma}\right) r_{x, 1}^{i}\right]=0
$$

where $r_{x, 1}^{i}, i=1,2$ and 3 , is the excess returns of all assets with respect to a reference asset, which in our case is the returns on foreign equity. Formally, the definitions are

$$
\begin{gathered}
\hat{r}_{x}^{1}=\hat{Y}_{1}^{H}+\hat{P}_{1}^{H h}-\hat{Y}_{1}^{F}-\hat{P}_{1}^{H f} \\
\hat{r}_{x}^{2}=-R_{0}^{H} \hat{P}_{1}^{H}-\hat{Y}_{1}^{F}-\hat{P}_{1}^{H f}-\hat{P}_{1}^{H} \\
\hat{r}_{x}^{3}=-R_{0}^{F} \hat{P}_{1}^{F}+\hat{Q}_{1}-\hat{Y}_{1}^{F}-\hat{P}_{1}^{H f}-\hat{P}_{1}^{H} .
\end{gathered}
$$

In other words, using the equilibrium conditions, we can write $\hat{C}_{1}^{H}-\hat{C}_{1}^{F}-\frac{\hat{Q}_{1}}{\sigma}=\Xi_{a}(\theta, z) * \zeta_{1}^{\prime}$ and $\hat{r}_{x, 1}=\Xi_{b}(\theta, z) * \zeta_{1}^{\prime}$, where $\zeta_{1}=\left[\begin{array}{llllll}\hat{Y}_{1}^{H} & \hat{Y}_{1}^{F} & G_{1}^{H f} & G_{1}^{F h} & \hat{P}_{1}^{H} & \hat{P}_{1}^{F}\end{array}\right]$ and $\hat{r}_{x, 1}^{\sigma}=\left[\begin{array}{lll}\hat{r}_{x}^{1} & \hat{r}_{x}^{2} & \hat{r}_{x}^{3}\end{array}\right]$. Then the solution for $\theta$ and $z$ is given by the following system of equations

$$
\Xi_{a}(\theta, z) \Sigma \Xi_{b}(\theta, z)^{\prime}=0
$$

where $\Sigma=E_{0}\left[\zeta_{1}^{\prime} \zeta_{1}\right]$. Again here we consider $\Sigma=I$.

In the case where there is no consumption bias of the agent, that is $a=0.5$, it implies that $\hat{Q}_{1}=$ 0 . Using demand and market-clearing conditions as well as the budget and resource constraints, we get

$$
\hat{C}_{1}^{H}-\hat{C}_{1}^{F}=\left(\begin{array}{c}
(-1+2 \theta)\left(1-\frac{1}{\eta}\right) \\
-(-1+2 \theta)\left(1-\frac{1}{\eta}\right) \\
-\left(1+2\left(\theta-\frac{1}{2}\right) \frac{1}{\eta} \frac{1-x}{1+x}\right) \\
\left(1+2\left(\theta-\frac{1}{2}\right) \frac{1}{\eta} \frac{1-x}{(1+x)}\right) \\
2 R_{0}(B-z) \\
-2 R_{0}(B-z)
\end{array}\right)^{\prime}\left(\begin{array}{c}
\hat{Y}_{1}^{H} \\
\hat{Y}_{1}^{F} \\
G_{1}^{H f} \\
G_{1}^{F h} \\
\hat{P}_{1}^{H} \\
\hat{P}_{1}^{F}
\end{array}\right)
$$


while $\hat{r}_{x}=\left(\begin{array}{c}\hat{r}_{x}^{1} \\ \hat{r}_{x}^{2}\end{array}\right)$ is given by

$$
\hat{r}_{x, 1}=\left(\begin{array}{cccccc}
1-\frac{1}{\eta} & \frac{1}{\eta}-1 & \frac{1}{\eta} \frac{x-1}{1+x} & -\frac{1}{\eta} \frac{x-1}{1+x} & 0 & 0 \\
-\frac{1}{2 \eta} & \frac{1}{2 \eta}-1 & \frac{1}{2 \eta} \frac{x-1}{1+x} & -\frac{1}{2 \eta} \frac{x-1}{1+x} & -R_{0} & 0
\end{array}\right)\left(\begin{array}{c}
\hat{Y}^{H} \\
\hat{Y}_{1}^{F} \\
G_{1}^{H f} \\
G_{1}^{F h} \\
\hat{P}_{1}^{H} \\
\hat{P}_{1}^{F}
\end{array}\right) .
$$

Then, using the methodology above (Eqn.(18)), we have a system of two equations and two variables that gives the following allocations:

$$
\begin{gathered}
\theta=\frac{1}{2}+\frac{1}{2} \frac{\eta\left(x^{2}-1\right)}{(\eta-1)^{2}(1+x)^{2}+2(1-x)^{2}} \\
z=B .
\end{gathered}
$$

Proposition 3: Upto a first-order, (i) in the presence of nominal, endowment, and government expenditure shocks, if (ii) the representative agent has log-utility, preference bias in consumption for domestic goods, and CES preferences over domestic and foreign goods, (iii) the government taxes only domestic agents, and (iv) the government expenditure ratio between domestic goods and foreign goods is $x$, then (a) there is home nominal bond bias (b) $x>\frac{a}{1-a}$ implies home equity bias.

Proof: The set of equations to be solved is given below. We can re-write the system as

$$
\begin{aligned}
& \left(\begin{array}{cccc}
-1 & 1 & 1 & -1 \\
a+\frac{(\theta-a)}{\eta} & 1-a-\frac{(\theta-a)}{\eta} & 0 & 0 \\
a & 0 & 1-a & 0 \\
0 & 1-a & 0 & a
\end{array}\right)\left(\begin{array}{c}
\hat{C}_{1}^{H h} \\
\hat{C}_{1}^{H f} \\
\hat{C}_{1}^{F h} \\
\hat{C}_{1}^{F f}
\end{array}\right)= \\
& =\left(\begin{array}{cccccc}
0 & 0 & 0 & 0 & 0 & 0 \\
\theta & -(\theta-1) & -x-1 & 0 & R_{0}(B-z) & -R_{0}(B-z) \\
1 & 0 & -x & -1 & 0 & 0 \\
0 & 1 & -1 & x & 0 & 0
\end{array}\right)\left(\begin{array}{c}
\hat{Y}^{H} \\
\hat{Y}^{F} \\
G^{H f} \\
G^{F h} \\
\hat{P}^{H} \\
\hat{P}^{F}
\end{array}\right)
\end{aligned}
$$

We can solve for the consumption levels in terms of the shocks. Using also that $\hat{Q}_{t}=(2 a-$ 1) $\left(\hat{P}^{H f}-\hat{P}^{H h}\right)$ we can re-write excess returns as

$$
r_{x, t}=\left(\begin{array}{cccccc}
1 & -1 & 0 & 0 & 0 & 0 \\
0 & -1 & 0 & 0 & -R_{0} & 0
\end{array}\right)\left(\begin{array}{c}
\hat{Y}^{H} \\
\hat{Y}^{F} \\
G^{H f} \\
G^{F h} \\
\hat{P}^{H} \\
\hat{P}^{F}
\end{array}\right)+\left(\begin{array}{c}
1 \\
a
\end{array}\right) \frac{\left(\hat{C}^{H h}-\hat{C}^{H f}\right)}{\eta} .
$$

We can use eqn.(18) for $\theta$ and $z$, using $\sigma=1$. The resulting expressions for $\theta$ and $z$, while closedform, are very cumbersome to put in text. We have shown using a symbolic package that $x>\frac{a}{1-a}$ 
is the sufficient condition to generate home bias in equity.

We report in the figure below the numerical results on asset holdings as we vary $x$ in this set-up for $\sigma=1.5$ and different values of $a$ and $\eta$.
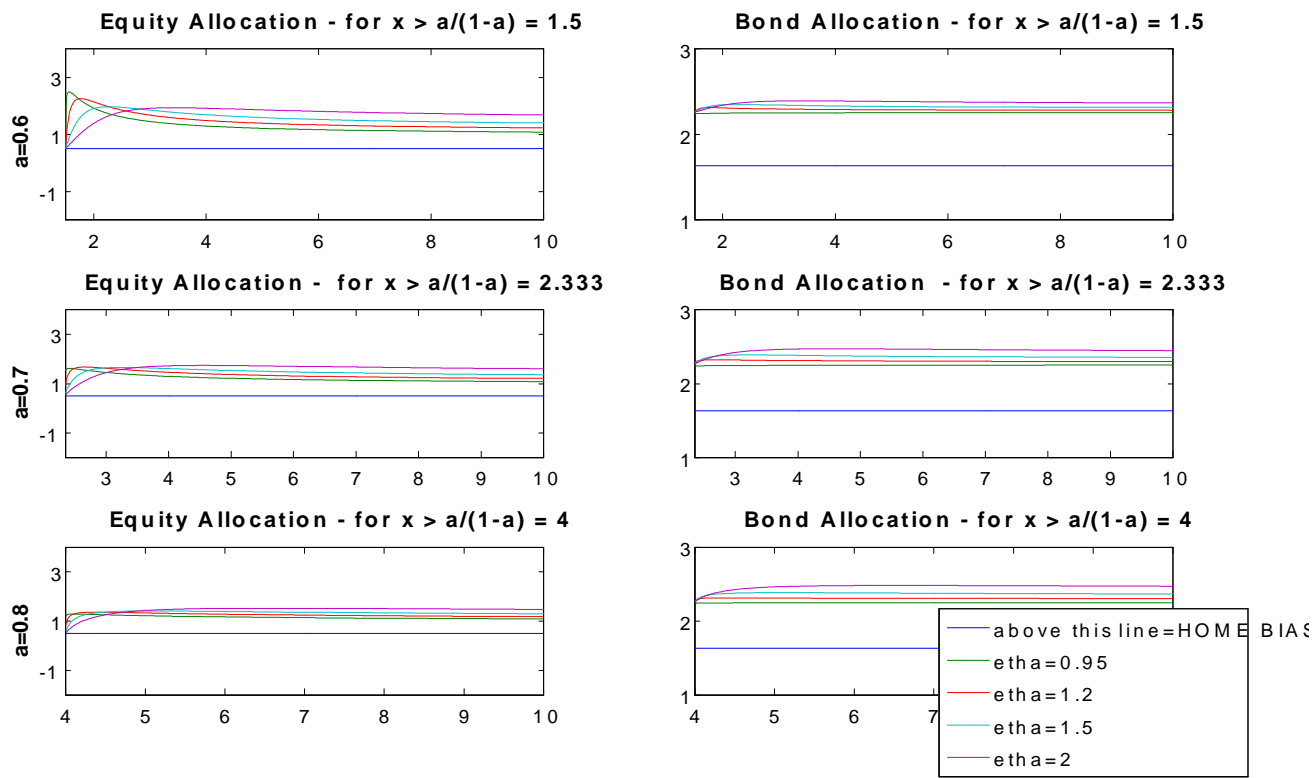

\subsection{Calibrated dynamic production economy}

\subsubsection{First-order approximation}

To solve the model, we use an approximation around a symmetric non-stochastic steady state where the net foreign assets of the countries, wealth of the consumer less government debt, is equal to zero. In addition, steady state aggregate consumption, aggregate price levels, and aggregate output are equal to one while government spending is equal to zero. Next, we present the system of log-linearized equations that are relevant for determining portfolio holdings.

Consumer The FOCs of the home agent log-linearized give

$$
\begin{gathered}
-\sigma \hat{C}_{t}^{H}=E_{t}\left[-\sigma \hat{C}_{t+1}^{H}+\hat{P}_{t}^{H}+\hat{R}_{t}^{H}-\hat{P}_{t+1}^{H}\right] \\
-\sigma \hat{C}_{t}^{H}=E_{t}\left[-\sigma \hat{C}_{t+1}^{H}+\hat{P}_{t}^{F}+\hat{R}_{t}^{F}-\hat{P}_{t+1}^{F}+\hat{Q}_{t+1}-\hat{Q}_{t}\right] \\
-\sigma \hat{C}_{t}^{H}=E_{t}\left[-\sigma \hat{C}_{t+1}^{H}+\beta \hat{q}_{t+1}^{H}-\hat{q}_{t}^{H}+(1-\beta) \Pi_{t+1}^{H}\right] \\
-\sigma \hat{C}_{t}^{H}=E_{t}\left[-\sigma \hat{C}_{t+1}^{H}+\beta \hat{q}_{t+1}^{F}-\hat{q}_{t}^{F}+(1-\beta) \Pi_{t+1}^{F}+\hat{Q}_{t+1}-\hat{Q}_{t}\right]
\end{gathered}
$$




$$
\nu \hat{L}_{t}^{H}=-\sigma \hat{C}_{t}^{H}+\hat{w}_{t}^{H}-\left(\frac{\bar{\tau}^{L}}{1-\bar{\tau}^{L}}\right) \hat{\tau}_{t}^{L}
$$

while the FOCs of the foreign agent log-linearized and combined with FOCs of the domestic agent gives

$$
-\sigma\left[\hat{C}_{t}^{H}-\hat{C}_{t}^{F}\right]+\hat{Q}_{t}=-\sigma E_{t}\left[\hat{C}_{t+1}^{H}-\hat{C}_{t+1}^{F}\right]+E_{t}\left[\hat{Q}_{t+1}\right] .
$$

Similarly the definitions of the various aggregate indices and the demand curve can be written as

$$
\begin{gathered}
\hat{C}_{t}^{H}=a \hat{C}_{t}^{H h}+(1-a) \hat{C}_{t}^{H f} \quad \hat{P}_{t}^{H}=a \hat{P}_{t}^{H h}+(1-a) \hat{P}_{t}^{H f} \\
\hat{C}_{t}^{H h}-\hat{C}_{t}^{H f}=\eta\left(\hat{P}_{t}^{H f}-\hat{P}_{t}^{H h}\right) .
\end{gathered}
$$

The real exchange rate can be expressed as

$$
\hat{Q}_{t}=\hat{S}_{t}+\hat{P}_{t}^{F}-\hat{P}_{t}^{H}
$$

and the law of one price in aggregate terms as

$$
\hat{P}_{t}^{H h}=\hat{S}_{t}+\hat{P}_{t}^{F h} \quad \hat{P}_{t}^{H f}=\hat{S}_{t}+\hat{P}_{t}^{F f} .
$$

Finally, the consumer's budget constraint can be written as

$$
\begin{aligned}
\hat{C}_{t}^{H}+\bar{B} \hat{W}_{t}^{H} & =\frac{1}{\beta} \bar{B}\left(\hat{W}_{t-1}^{H}+\hat{r}_{t}^{1}\right)-\left(\bar{\tau}^{L} \bar{w}\right) \hat{\tau}_{t}^{L}+ \\
& \left(1-\bar{\tau}^{L}\right) \bar{w}\left(\hat{w}_{t}^{H}+\hat{L}_{t}^{H}\right)+\frac{\bar{B}^{H f}}{\beta} \hat{r}_{x, t}^{1}+\frac{\bar{q}^{H} \bar{A}^{H h}}{\beta} \hat{r}_{x, t}^{2}+\frac{\bar{q}^{F} \bar{A}^{H f}}{\beta} \hat{r}_{x, t}^{3}
\end{aligned}
$$

where

$$
\hat{r}_{t}^{1}=\hat{P}_{t-1}^{H}+\hat{R}_{t-1}^{H}-\hat{P}_{t}^{H}
$$

is the real return on domestic nominal bonds and

$$
\begin{gathered}
\hat{r}_{x, t}^{1}=\left(\hat{P}_{t-1}^{F}+\hat{R}_{t-1}^{F}-\hat{P}_{t}^{F}+\hat{Q}_{t}-\hat{Q}_{t-1}\right)-\hat{r}_{t}^{1} \\
\hat{r}_{x, t}^{2}=\left(\beta \hat{q}_{t}^{H}-\hat{q}_{t-1}^{H}+(1-\beta) \Pi_{t}^{H}\right)-\hat{r}_{t}^{1} \\
\hat{r}_{x, t}^{3}=\left(\beta \hat{q}_{t}^{F}-\hat{q}_{t-1}^{F}+(1-\beta) \Pi_{t}^{F}+\hat{Q}_{t}-\hat{Q}_{t-1}\right)-\hat{r}_{t}^{1}
\end{gathered}
$$

are the excess returns of foreign nominal bonds, domestic equity, and foreign equity over domestic nominal bonds.

Firms The aggregate production technology log-linearized yields

$$
\hat{Y}_{t}^{H}=\hat{A}_{t}^{H}+\hat{L}_{t}^{H}
$$

while profits and the pricing rule are given by 


$$
\begin{gathered}
\hat{\Pi}_{t}^{H}=\theta\left[-\bar{w}\left(\hat{w}_{t}^{H}+\hat{Y}_{t}^{H}-\hat{A}_{t}^{H}\right)+\left(\hat{P}_{t}^{H h}-\hat{P}_{t}^{H}+\hat{Y}_{t}^{H}\right)\right]-\left(\frac{\bar{\tau}^{\Pi}}{1-\bar{\tau}^{\Pi}}\right) \hat{\tau}_{t}^{\pi} \\
\hat{P}_{t}^{H h}-\hat{P}_{t}^{H}=\hat{w}_{t}^{H}-\hat{A}_{t}^{H} .
\end{gathered}
$$

Government The government budget constraint can be expressed as

$$
\bar{B}\left(\hat{B}_{t}-\hat{P}_{t}^{H}\right)=\beta^{-1} \bar{B}\left(\hat{R}_{t-1}^{H}+\hat{B}_{t-1}-\hat{P}_{t}^{H}\right)-\left(1+\frac{1}{y}\right) \bar{\tau}^{L} \bar{w}\left(\hat{\tau}_{t}^{L}+\hat{w}_{t}^{H}+\hat{L}_{t}^{H}\right)+G_{t}^{H h}+G_{t}^{H f}
$$

Moreover, we can write the monetary policy rule as

$$
\hat{R}_{t}^{H}=\gamma\left(\hat{P}_{t}^{H}-\hat{P}_{t-1}^{H}\right)+\epsilon_{r, t}
$$

and the fiscal policy rule as

$$
\hat{\tau}_{t}^{L}+\hat{w}_{t}^{H}+\hat{L}_{t}^{H}=\phi\left(\hat{B}_{t}-\hat{P}_{t}^{H}\right)
$$

The relationship between government spending on domestic and foreign goods, and the tax revenues through labor and profits can be written as

$$
\begin{gathered}
G_{t}^{H h}=x G_{t}^{H f} \\
\hat{\tau}_{t}^{L}+\hat{w}_{t}^{H}+\hat{L}_{t}^{H}=\hat{\tau}_{t}^{\pi}+\hat{Y}_{t}^{H}-\theta\left(\hat{P}_{t}^{H}-\hat{P}_{t}^{H h}\right)-(\theta-1)\left(\hat{w}_{t}^{H}-\hat{A}_{t}^{H}\right) .
\end{gathered}
$$

Market clearing The market clearing condition for goods at the aggregate level can be expressed as

$$
a \hat{C}_{t}^{H h}+(1-a) \hat{C}_{t}^{F h}+G_{t}^{H h}+G_{t}^{F h}=\hat{Y}_{t}^{H} \quad \hat{C}_{t}^{F f}+\hat{C}_{t}^{H f}+G_{t}^{H f}+G_{t}^{F f}=\hat{Y}_{t}^{F}
$$

while the asset market clearing condition in terms of steady state values are given by

$$
\begin{array}{ll}
\bar{E}^{H h}+\bar{E}^{F h}=1 & \bar{E}^{H f}+\bar{E}^{F f}=1 \\
\bar{B}^{H h}+\bar{B}^{F h}=\bar{B} & \bar{B}^{H f}+\bar{B}^{F f}=\bar{B}^{F} .
\end{array}
$$

\subsubsection{Solution for steady-state portfolio}

The technique used to determine steady state portfolio holdings under incomplete markets is the same as described earlier for the two-period model. That is, we take second order approximations of the domestic and foreign consumer's euler equations and combine them to get

$$
E_{t}\left[\left(\hat{C}_{t+1}^{H}-\hat{C}_{t+1}^{F}-\frac{\hat{Q}_{t+1}}{\sigma}\right) \hat{r}_{x, t+1}^{i}\right]=0 ; \quad i=1: 3 .
$$

Then, we solve the system of equations up to first order approximation for given values of $\bar{B}^{H f}, \bar{A}^{H h}$, and $\bar{A}^{H f}$. Then, we check if the resulting dynamics of variables satisfy the euler equations upto second 
order accuracy. We iterate until a fixed-point for the asset holdings is found.

\subsubsection{Moments of the calibrated model}

We report below some standard open economy business cycle moments produced from a simulation of our calibrated model. The data counterparts are taken from Backus and Kehoe (1992) and Corsetti e tal (2008).

\begin{tabular}{lcc}
\hline \hline \multicolumn{3}{c}{ Moments of calibrated Model } \\
Volatilities & & \\
& Data & Model \\
Consumption & $1.47 \%$ & $1.86 \%$ \\
Trade Balance & $0.97 \%$ & $1.77 \%$ \\
& & \\
St. Dev. Relative to GDP & Data & Model \\
& 3.9 & 0.5 \\
Real Exchange Rate & 1.7 & 1.0 \\
Terms of Trade & 0.9 & 1.0 \\
Consumption & 1.2 & 0.3 \\
Employment & & \\
& & \\
Correlations & Data & Model \\
& & \\
& 0.82 & 0.37 \\
Consumption and GDP & -0.2 & 0.32 \\
Trade Balance and GDP & -0.33 & -0.73 \\
ToT and Relative GDPs & -0.74 & -0.92 \\
ToT and Relative Consumption & & \\
\hline \hline
\end{tabular}

\subsection{Extensions of the dynamic production economy}

Here we provide details on the extended model that features a term structure of government debt and capital as an input in production.

A representative agent at home maximizes the expected present discounted value of utility

$$
E_{t} \sum_{t=0}^{\infty} \beta^{t}\left[\frac{\left(C_{t}^{H}\right)^{1-\sigma}}{1-\sigma}-\lambda \frac{\left(L_{t}^{H}\right)^{1+\nu}}{1+\nu}\right] \quad 0<\beta<1, \sigma>0, \nu>0, \lambda>0
$$

where $C_{t}^{H}$ is the composite domestic consumption good and $L_{t}^{H}$ is domestic labor supply. The agent is subject to the period budget constraint

$$
C_{t}^{H}+Z_{t}^{H, m} \frac{B_{t}^{H h, m}}{P_{t}^{H}}+Z_{t}^{F, m} \frac{B_{t}^{H f, m}}{P_{t}^{F}} Q_{t}+q_{t}^{H} E_{t}^{H h}+q_{t}^{F} E_{t}^{H f} Q_{t}=\left(1-\tau_{t}^{L}\right) w_{t}^{H} L_{t}^{H}+r_{t}^{H} K^{H}
$$




$$
+\frac{\left(1+\rho Z_{t}^{H, m}\right) B_{t-1}^{H h, m}}{P_{t}^{H}}+\frac{\left(1+\rho Z_{t}^{F, m}\right) B_{t-1}^{H f, m}}{P_{t}^{F}} Q_{t}+\left(q_{t}^{H}+\Pi_{t}^{H}\right) E_{t-1}^{H h}+\left(q_{t}^{F}+\Pi_{t}^{F}\right) Q_{t} E_{t-1}^{H f} .
$$

where $B_{t-1}^{H h, m}, B_{t-1}^{H f, m}, E_{t-1}^{H h}$, and $E_{t-1}^{H f}$ are holdings of domestic nominal bonds, foreign nominal bonds, claims to aggregate after-tax profits of domestic firms, and claims to aggregate after-tax profits of foreign firms purchased in period $t-1$ to be brought into period $t$. The domestic agents thus simply owns the capital stock $K^{H}$ and rents it out to firms at the rate $r_{t}^{H}$ in a competitive market. Note that here the bonds are a general portfolio of infinitely many bonds and $\rho$ determines the average maturity of debt. We describe this set-up in detail later below.

Moreover, $P_{t}^{H}$ is the aggregate domestic price level, $P_{t}^{F}$ is the aggregate foreign price level, $Q_{t}$ is the real exchange rate, $q_{t}^{H}$ is the (real) price of one unit of claim to domestic profits, $q_{t}^{F}$ is the (real) price of one unit of claim to foreign endowment, $\Pi_{t}^{H}$ is after-tax aggregate real profits of domestic firms, $\Pi_{t}^{F}$ is after-tax aggregate real profits of foreign firms, $Z_{t}^{H, m}$ is the price of domestic bonds, $Z_{t}^{F, m}$ is the price of foreign bonds, $\tau_{t}^{L}$ is the rate of labor income tax, and $w_{t}^{H}$ is the real wage at home.

The composite consumption good $C_{t}^{H}$ is a CES aggregate of domestic $C_{t}^{H h}$ and foreign $C_{t}^{H f}$ final goods. The home consumption good $C_{t}^{H h}$ is produced in differentiated brands $c_{t}^{H h}$ by a continuum of monopolistically competitive home firms indexed $j$ and of measure 1 , and is defined as

$$
C_{t}^{H h}=\left[\int_{0}^{1} c_{t}^{H h}(j)^{\frac{\theta-1}{\theta}} d j\right]^{\frac{\theta}{\theta-1}} \theta>1
$$

where the elasticity of substitution among the brands is given by $\theta$. Similarly, the foreign consumption good $C_{t}^{H f}$ is produced in differentiated brands $c_{t}^{H f}$ by a continuum of monopolistically competitive foreign firms indexed $f$ and of measure 1 , and is defined as

$$
C_{t}^{H f}=\left[\int_{0}^{1} c_{t}^{H f}(f)^{\frac{\theta-1}{\theta}} d f\right]^{\frac{\theta}{\theta-1}}
$$

where the elasticity of substitution among the brands is given by $\theta$.

As is well known, expenditure minimization by the agent will imply a utility-based aggregate price index at home, $P_{t}^{H}$. Expenditure minimization will also imply the following domestic price level of the home consumption good $P_{t}^{H h}=\left[\int_{0}^{1} p_{t}^{H h}(j)^{1-\theta} d j\right]^{\frac{1}{1-\theta}}$, where $p_{t}^{H h}(j)$ is the domestic price level of brand $j$ of the domestic good, and the following domestic price level of the foreign consumption good $P_{t}^{H f}=\left[\int_{0}^{1} p_{t}^{H f}(f)^{1-\theta} d f\right]^{\frac{1}{1-\theta}}$, where $p_{t}^{H f}(f)$ is the domestic price level of brand $f$ of the foreign good.

Similarly, given the definition of the consumption goods and the price levels, manipulation of the demand curves at the brand level gives

$$
\frac{c_{t}^{H h}(j)}{C_{t}^{H h}}=\left(\frac{p_{t}^{H h}(j)}{P_{t}^{H h}}\right)^{-\theta} \quad \frac{c_{t}^{H f}(j)}{C_{t}^{H f}}=\left(\frac{p_{t}^{H f}(j)}{P_{t}^{H f}}\right)^{-\theta} .
$$

The law of one price holds among the tradable brands and hence we have

$$
p_{t}^{H h}(j)=S_{t} p_{t}^{F h}(j) \quad p_{t}^{H f}(f)=S_{t} p_{t}^{F f}(f)
$$


where $p_{t}^{F h}(j)$ and $p_{t}^{F f}(f)$ are the foreign price level of price of the brand $j$ of the domestic good and brand $f$ of the foreign good.

Given the definition of the consumption indices and the price indices resulting from expenditure minimization, the optimization problem of the consumer results in

$$
\begin{gathered}
\frac{1}{\left(C_{t}^{H}\right)^{\sigma}}=E_{t}\left[\frac{\beta P_{t}^{H}\left(1+\rho Z_{t+1}^{H, m}\right)}{\left(C_{t+1}^{H}\right)^{\sigma} P_{t+1}^{H} Z_{t}^{H, m}}\right]=E_{t}\left[\frac{\beta P_{t}^{F}\left(1+\rho Z_{t+1}^{F, m}\right) Q_{t+1}}{\left(C_{t+1}^{H}\right)^{\sigma} P_{t+1}^{F} Z_{t}^{F, m} Q_{t}}\right] \\
\frac{1}{\left(C_{t}^{H}\right)^{\sigma}}=E_{t}\left[\frac{\beta\left(q_{t+1}^{H}+\Pi_{t+1}^{H}\right)}{\left(C_{t+1}^{H}\right)^{\sigma} q_{t}^{H}}\right]=E_{t}\left[\frac{\beta\left(q_{t+1}^{F}+\Pi_{t+1}^{F}\right) Q_{t+1}}{\left(C_{t+1}^{H}\right)^{\sigma} q_{t}^{F} Q_{t}}\right] \\
\lambda\left(L_{t}^{H}\right)^{\nu}=\left(C_{t}^{H}\right)^{-\sigma}\left(1-\tau_{t}^{L}\right) w_{t}^{H} .
\end{gathered}
$$

Each brand $j$ of the domestic good is produced by a single home firm $j$ using the following production function

$$
y_{t}^{H}(j)=A_{t}^{H}\left(l_{t}^{H}(j)\right)^{\alpha}\left(k_{t}^{H}(j)\right)^{1-\alpha}
$$

where $y_{t}^{H}(j)$ is the domestic output of brand $j, A_{t}^{H}$ is the country-specific productivity shock that follows an exogenous process, $l_{t}^{H}(j)$ is the labor demand by firm $j$, and $k_{t}^{H}(j)$ is capital used in production by firm $j$ and $\alpha$ is the share of labor. Firms hire labor and capital in a competitive market taking the wage and rental rate of capital as given. The labor and capital used is homogenous across all firms $j$. The firms are identical except for the fact that they produce differentiated brands for the same good. The process for productivity is given by $\log A_{t}^{H}=\rho_{A} \log A_{t-1}^{H}+\epsilon_{a, t}$. The supply of capital is fixed in the aggregate.

The optimal choice of inputs by firms is given by

$$
\frac{w_{t}^{H} l_{t}^{H}(j)}{r_{t}^{H} k_{t}^{H}(j)}=\frac{\alpha}{1-\alpha}
$$

where $r_{t}$ is the rental rate of capital and the nominal marginal cost is given by

$$
M C_{t}=\frac{1}{(1-\alpha)^{1-\alpha} \alpha^{\alpha}} \frac{P_{t}^{H}\left(w_{t}^{H}\right)^{\alpha}\left(r_{t}^{H}\right)^{1-\alpha}}{A_{t}^{H}} .
$$

Firm $j$ maximizes real profits, that is revenue less labor costs, given by

$$
\frac{p_{t}^{H h}(j) y_{t}^{H}(j)}{P_{t}^{H}}-w_{t}^{H} l_{t}^{H}(j)-r_{t}^{H} k_{t}^{H}(j)
$$

leading to the familiar pricing equation

$$
p_{t}^{H h}(j)=\frac{\theta}{\theta-1} \frac{P_{t}^{H}}{A_{t}^{H}}\left(\frac{\left(w_{t}^{H}\right)^{\alpha}\left(r_{t}^{H}\right)^{1-\alpha}}{(1-\alpha)^{1-\alpha} \alpha^{\alpha}}\right)
$$

where monopolistically competitive firms charge a price that is a mark-up times the nominal marginal cost $M C_{t}$.

The aggregate after tax real profits of the firms in the domestic economy can be written as 


$$
\Pi_{t}^{H}=\left(1-\tau_{t}^{\pi}\right)\left(P_{t}^{H h}-\frac{\left(w_{t}^{H}\right)^{\alpha}\left(r_{t}^{H}\right)^{1-\alpha}}{(1-\alpha)^{1-\alpha} \alpha^{\alpha} A_{t}^{H}} P_{t}^{H}\right) \frac{Y_{t}^{H}}{P_{t}^{H}}
$$

and the optimization decision of the individual domestic firms gives

$$
\frac{P_{t}^{H h}}{P_{t}^{H}}=\frac{\theta}{\theta-1} \frac{\left(w_{t}^{H}\right)^{\alpha}\left(r_{t}^{H}\right)^{1-\alpha}}{(1-\alpha)^{1-\alpha} \alpha^{\alpha} A_{t}^{H}} .
$$

The optimization problem of the foreign firms is entirely analogous and is not presented here to conserve space.

For government debt, rather than considering only one-period debt, we follow Woodford (2001) and allow for the existence of a general portfolio of government debt $B_{t}^{H, m}$ that has price $Z_{t}^{H, m}{ }^{2}$ Households engage on trade of this general government debt instrument. In particular, this instrument's payment structure is $\rho^{T-(t+1)}$ for $T>t$ and $0 \leq \rho \leq 1$. Thus, the value of this portfolio of bond issued in period $t$ in $t+j$ is given by $Z_{t+j}^{H, m-j}=\rho^{j} Z_{t+j}^{H, m}$. We interpret this general instrument as a portfolio of infinitely many bonds, whose weights are given by $\rho^{T-(t+1)} \cdot \rho$ thus determines the average maturity of government debt: when $\rho=0$, all debt is of one-period maturity. ${ }^{3}$ The period home government budget constraint in this set-up is then given by

$$
\begin{aligned}
Z_{t}^{H, m} \frac{B_{t}^{H, m}}{P_{t}^{H}}= & \frac{B_{t-1}^{H, m}}{P_{t}^{H}}\left(1+\rho Z_{t}^{H, m}\right)-\tau_{t}^{L} w_{t}^{H} L_{t}^{H}-\tau_{t}^{\pi}\left(P_{t}^{H h}-\frac{\left(w_{t}^{H}\right)^{\alpha}\left(r_{t}^{H}\right)^{1-\alpha}}{(1-\alpha)^{1-\alpha} \alpha^{\alpha} A_{t}^{H}} P_{t}^{H}\right) \frac{Y_{t}^{H}}{P_{t}^{H}} \\
& +G_{t}^{H h} \frac{P_{t}^{H h}}{P_{t}^{H}}+G_{t}^{H f} \frac{P_{t}^{H f}}{P_{t}^{H}}
\end{aligned}
$$

where $B_{t}^{H, m}$ is total nominal debt issued by the home government in period $t$ and $G_{t}^{H h}$ and $G_{t}^{H f}$ respectively are the home government's spending on domestic and foreign good. The ratio of labor tax revenue vs. profit tax revenue is for simplicity, constant

$$
\tau_{t}^{L} w_{t}^{H} L_{t}^{H}=y\left[\tau_{t}^{\pi}\left(P_{t}^{H h}-\frac{\left(w_{t}^{H}\right)^{\alpha}\left(r_{t}^{H}\right)^{1-\alpha}}{(1-\alpha)^{1-\alpha} \alpha^{\alpha} A_{t}^{H}} P_{t}^{H}\right) \frac{Y_{t}^{H}}{P_{t}^{H}}\right]
$$

where $y$ is a parameter of our model.

We assume here that government spending over the differentiated brands of the domestic and foreign goods is defined in the same way as for the consumer with the same elasticity of substitution over the brands. That is,

$$
G_{t}^{H h}=\left[\int_{0}^{1} g_{t}^{H h}(j)^{\frac{\theta-1}{\theta}} d j\right]^{\frac{\theta}{\theta-1}} \quad G_{t}^{H f}=\left[\int_{0}^{1} g_{t}^{H f}(f)^{\frac{\theta-1}{\theta}} d f\right]^{\frac{\theta}{\theta-1}} .
$$

The ratio of government spending over domestic vs. foreign good is for simplicity, constant

$$
G_{t}^{H h}=x G_{t}^{H f}
$$

\footnotetext{
${ }^{2}$ Here we use the index $m$ to denote the fact that this bond has a certain duration in period $t$.

${ }^{3}$ The average maturity of the portfolio is given by $(1-\beta \rho)^{-1}$.
} 
where $x$ is a parameter of our model. Government spending follows an exogenous process

$$
G_{t}^{H}=G_{t}^{F h}\left(\frac{P_{t}^{F h}}{P_{t}^{F} Q_{t}}\right)+G_{t}^{F f}\left(\frac{P_{t}^{F f}}{P_{t}^{F}}\right)=\rho_{G} G_{t-1}^{H h}+\epsilon_{g, t} .
$$

We do not consider explicit optimal government policy and use simple rules as descriptions of government policy. The government conducts monetary policy using a version of the interest rate rule given by

$$
\left(\frac{1+\rho Z_{t+1}^{H, m}}{Z_{t}^{H, m}}\right)=\gamma_{0}\left(P_{t}^{H} / P_{t-1}^{H}\right)^{\gamma} \exp \left(\epsilon_{r, t}^{H}\right)
$$

where the interest rate shock follows the exogenous process $\log \epsilon_{r, t}^{H}=\rho_{R} \log \epsilon_{r, t-1}^{H}+e_{r, t}$ and fiscal policy using a rule for total tax revenue responding to real value of debt

$$
\tau_{t}^{L} w_{t}^{H} L_{t}^{H}+\tau_{t}^{\pi}\left(P_{t}^{H h}-\frac{\left(w_{t}^{H}\right)^{\alpha}\left(r_{t}^{H}\right)^{1-\alpha}}{(1-\alpha)^{1-\alpha} \alpha^{\alpha} A_{t}^{H}} P_{t}^{H}\right) \frac{Y_{t}^{H}}{P_{t}^{H}}=\phi_{0}\left(\frac{B_{t}^{H}}{P_{t}^{H}}\right)^{\phi} .
$$

Again, the foreign government's description is completely analogous and symmetric.

Market clearing for goods implies

$$
\begin{aligned}
c_{t}^{H h}(j)+c_{t}^{F h}(j)+g_{t}^{H h}(j)+g_{t}^{F h}(j) & =A_{t}^{H}\left(l_{t}^{H}(j)\right)^{\alpha}\left(k_{t}^{H}(j)\right)^{1-\alpha} \\
c_{t}^{F f}(f)+c_{t}^{H f}(f)+g_{t}^{H f}(f)+g_{t}^{F f}(f) & =A_{t}^{F}\left(l_{t}^{F}(j)\right)^{\alpha}\left(k_{t}^{F}(j)\right)^{1-\alpha}
\end{aligned}
$$

while market clearing for assets implies

$$
\begin{aligned}
E_{t}^{H h}+E_{t}^{F h} & =1 \quad E_{t}^{H f}+E_{t}^{F f}=1 \\
B_{t}^{H h, m}+B_{t}^{F h, m} & =B_{t}^{H, m} \quad B_{t}^{H f, m}+B_{t}^{F f, m}=B_{t}^{F, m}
\end{aligned}
$$

and total labor demand by firms equaling labor supply and capital being fixed in the aggregate implies

$$
\begin{gathered}
\int_{0}^{1} l_{t}^{H}(j) d j=L_{t}^{H} \\
\int_{0}^{1} k_{t}^{H}(j) d j=K_{t}^{H}=K^{H} .
\end{gathered}
$$

We next provide results for asset holdings when we shut down government spending shocks in the model

\begin{tabular}{cc}
\hline \hline Domestic Holdings - Model Extension \\
No Govnt Expenditure Shock \\
\\
Bonds & $-525 \%$ \\
Equity & $-163 \%$ \\
\hline \hline
\end{tabular}




\subsection{VAR methodology}

We have

$$
\hat{b}_{t-1}=-E_{t-1}\left[\sum_{s=0}^{\infty}(\bar{\rho})^{s} \tilde{r}_{t+s}\right]-\bar{\rho}\left[E_{t-1} \sum_{s=0}^{\infty}(\bar{\rho})^{s}\left[\hat{d}_{t+s}\right]\right]
$$

which we rewrite as

$$
\hat{b}_{t}=-E_{t}\left[\sum_{s=1}^{\infty}(\bar{\rho})^{s-1} \tilde{r}_{t+s}\right]-\bar{\rho}\left[E_{t} \sum_{s=1}^{\infty}(\bar{\rho})^{s-1}\left[\hat{d}_{t+s}\right]\right] .
$$

Now lets derive the VAR representation that we need to compute the RHS of this expression. We will estimate the following $\operatorname{VAR}(\mathrm{p})$ where $y_{t}=\left(\tilde{r}_{t}, d_{t}, \hat{b}_{t}\right)^{\prime}$

$$
y_{t}=\phi_{1} y_{t-1}+\phi_{2} y_{t-2}+. .+\phi_{p} y_{t-p}+\epsilon_{t} .
$$

Next, it is convenient to write the VAR (p) in a $\operatorname{VAR}(1)$ form, by stacking appropriately

$$
\bar{y}_{t}=\phi \bar{y}_{t-1}+\bar{\epsilon}_{t}
$$

where $\bar{y}_{t}=\left(y_{t}^{\prime}, y_{t-1}^{\prime}, \ldots, y_{t-p+1}^{\prime}\right)^{\prime}, \bar{\epsilon}_{t}=\left(\bar{\epsilon}_{t}^{\prime}, 0\right)$, and $\phi$ is the companion matrix

$$
\phi=\left[\begin{array}{cccccc}
\phi_{1} & \phi_{2} & \phi_{3} & . . & \phi_{p-1} & \phi_{p} \\
I & 0 & 0 & \ldots & 0 & 0 \\
0 & I & 0 & \ldots & 0 & 0 \\
\ldots & \ldots & \ldots & \ldots & \ldots & . . \\
0 & 0 & 0 & . . & I & 0
\end{array}\right] .
$$

Here $I$ is a $3 * 3$ identity matrix and 0 is a $3 * 3$ matrix of zeros.

Then, given this VAR (1) notation, we have

$$
E_{t} \bar{y}_{t+s}=\phi^{s} \bar{y}_{t} .
$$

Also, define the following vectors that pick out the relevant elements from $\bar{y}_{t}$

$$
\begin{gathered}
e^{r}=\left[\begin{array}{ll}
1 & 0_{p-1}
\end{array}\right] ; e^{r} \bar{y}_{t}=\tilde{r}_{t} \\
e^{d}=\left[\begin{array}{lll}
0 & 1 & 0_{p-2}
\end{array}\right] ; e^{d} \bar{y}_{t}=d_{t} \\
e^{b}=\left[\begin{array}{llll}
0 & 0 & 1 & 0_{p-3}
\end{array}\right] ; e^{b} \bar{y}_{t}=\hat{b}_{t} .
\end{gathered}
$$

Next, we can then derive the two components of the RHS of the intertermporal budget constraint

$$
b_{t}^{r}=-\sum_{s=1}^{\infty}(\bar{\rho})^{s-1} E_{t} \tilde{r}_{t+s}
$$




$$
\begin{aligned}
& =-e^{r} \sum_{s=1}^{\infty}(\bar{\rho})^{s-1} \phi^{s} \bar{y}_{t} \\
& =-e^{r} \phi(I-\bar{\rho} \phi)^{-1} \bar{y}_{t} .
\end{aligned}
$$

Similarly, we have

$$
\begin{gathered}
b_{t}^{d}=-\bar{\rho} \sum_{s=1}^{\infty}(\bar{\rho})^{s-1} E_{t} \hat{d}_{t+s} \\
=-e^{d} \bar{\rho} \sum_{s=1}^{\infty}(\bar{\rho})^{s-1} \phi^{s} \bar{y}_{t} \\
=-e^{d}(\bar{\rho}) \phi(I-\bar{\rho} \phi)^{-1} \bar{y}_{t} .
\end{gathered}
$$

Given the estimates of $\phi$ and our resulting estimates for $b_{t}^{d}$, we then compute the correlations between $\tilde{r}_{t+1}$ and $b_{t}^{d}$ and between $\pi_{t+1}$ and $-b_{t}^{d}$. 


\section{References}

[1] Backus, D. K., P. J. Kehoe, 1992, "International Evidence of the Historical Properties of Business Cycles," American Economic Review, 82, 864-88.

[2] Corsetti, G., L. Dedola, S. Leduc, 2008, "International Risk Sharing and the Transmission of Productivity Shocks," Review of Economic Studies, 75, 444-73. 